\title{
A methods study of immobilization of PONOP pincer transition metal complexes on silica polyamine composites (SPC)
}

\author{
by \\ Md Abdul Goni, Edward Rosenberg ${ }^{*}$, Shesharao Meregude, Geoffrey Abbott \\ Department of Chemistry and Biochemistry, University of Montana, Missoula MT 59812
}

Corresponding author: Edward Rosenberg, email: edward.rosenberg@mso.umt.edu

\begin{abstract}
Immobilization of catalytically active transition metal complexes on silica polyamine composite (SPC) surfaces offers many advantages for applications in catalysis particularly for catalyst recovery and reuse. We report here the immobilization of PONOP pincer complexes of $R u, R h$, $\mathrm{Ni}$ and Pd on the poly(allylamine) SPC, BP-1 using the Mannich reaction. Three different methods have been investigated for synthesizing the PONOP pincer transition metal complexes on BP-1: 1) direct reaction of the preformed pincer complexes using a two step Mannich reaction; 2) immobilization of the PONOP ligand using the Mannich reaction followed by the addition of a transition metal compound of a given metal; 3) the stepwise construction of PONOP on BP-1 followed by addition of a transition metal compound. The immobilized complexes on BP-1 were characterized by FT-IR, solid-state CPMAS ${ }^{13} \mathrm{C}$ and ${ }^{31} \mathrm{P}$ NMR, as well as elemental analysis. Anchoring of the complexes on BP-1 was also evaluated by the metal loading data obtained from the digestion of the loaded composites followed by Atomic Absorption Spectroscopy (AAS) or Inductively Coupled Plasma Atomic Emission Spectroscopy
\end{abstract}


(ICPAES). The results showed that method 1 works better for the loading of pincer complexes on the SPC than methods 2 and 3. In the case of the $\mathrm{Ru}$ and $\mathrm{Ni}$ pincer complexes reasonable agreement with the phosphorous analysis was realized, while for the Pd complex values were high relative to the loading predicted from the phosphorus analysis, indicating the formation of the Pd nanoparticles on the surface during immobilization. For the $\mathrm{Rh}$ and $\mathrm{Ru}$ immobilized complexes with methods $2 \& 3$, metal loading was lower than the phosphorous analysis and this is attributed to entrained triphenylphosphine from the starting rhodium and ruthenium complexes based on the ${ }^{13} \mathrm{C}$ and ${ }^{31} \mathrm{P}$ CPMAS NMR data. Solution experiments using the PONOP pincer ligand and the $\mathrm{Ru}(\mathrm{PONOP})$ complex with n-butyl amine were conducted to model the site of electrophilic aromatic substitution on the pyridine ring. It was found that substitution both metaand para- to the nitrogen takes place and this helped in the interpretation of the solid-state data. Key words: PONOP, pincer complexes, composite materials, solid- state NMR

\section{Introduction}

The chemistry of metal pincer complexes has received significant attention in recent years. Pincer complexes have been shown to act as either catalysts or catalyst precursors. High tunability and thermal stability of the pincer complexes make them ideally suitable to a broad range of catalytic and stoichiometric transformations (Scheme 1). These include various bond activation reactions ${ }^{[1-2]}$, carbon-carbon bond forming reactions ${ }^{[3-4]}$, reduction of carbon dioxide

into useful chemicals ${ }^{[5]}$, conversion of nitrogen and hydrogen into ammonia ${ }^{[6]}$, polymerization reactions ${ }^{[7]}$, organic synthesis ${ }^{[8]}$ and supramolecular chemistry ${ }^{[9]}$. Though a large number of pincer ligands and their metal complexes are now accessible (Scheme 1), still they are relatively expensive and their synthetic procedures are not very straightforward. 


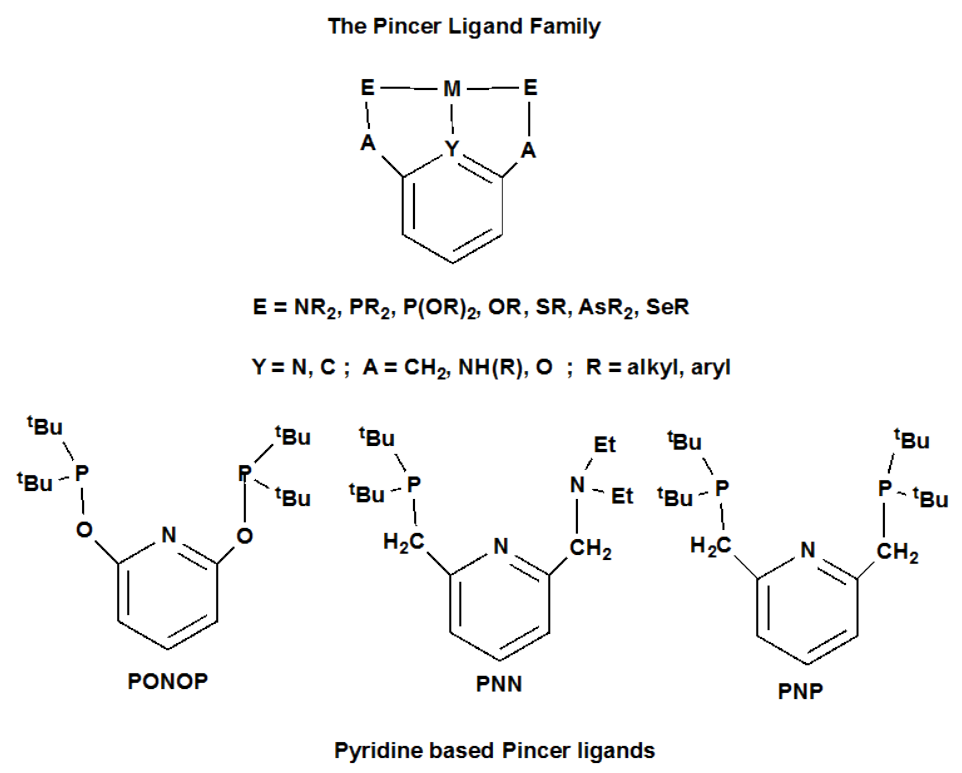

Scheme 1: General formula for pincer ligand-complexes and commonly used ligands

The immobilization of well-defined homogeneous catalysts onto a suitable support has been shown to be a promising and viable method for recycling catalysts after use in a catalytic reaction. ${ }^{[10-14]}$ Immobilization provides a means for separating pincer catalysts by simple filtration. In addition, the immobilization can increase catalyst stability as well as offering the possibility of enhancing selectivity. ${ }^{13}$ However, immobilization can often decrease the catalyst's activity. ${ }^{[13-16]}$

Several methods have been reported for immobilization of metal complexes on solid supports including physisorption, covalent ligand binding, ion pairing and encapsulation. ${ }^{[17-18]}$ However, immobilization by covalent attachment of ligands and metal complexes on a suitable inorganic solid support provides the best way of recycling homogeneous catalysts. ${ }^{[19]}$ Recent studies have reported various methods of immobilizing pincer complexes on a range of solid supports, including inorganic materials (alumina, silica), dendrimers and functionalized organic polymers. $^{[20-22]}$ Silica materials appear to be most suitable solids for immobilization of organometallic pincer catalysts. ${ }^{[23-24]}$ Pozo et. al. reported the immobilization of (NHC)NN- 
pincer complexes on mesoporous silica, MCM-41 support by covalent binding of the pincers to silica via a pendant alkoxysilane group. ${ }^{[19]}$ Platinum and palladium pincers, $\left[\mathrm{C}_{6} \mathrm{H}_{3}(2,6-\right.$ $\left.\mathrm{CH}_{2} \mathrm{NMe}_{2}\right)_{2}$ ] catalysts functionalized with para-ethynyl-groups were immobilized on azidofunctionalized silica materials for C-C coupling reactions using "click " chemistry. ${ }^{[25]}$ Palladium PCP pincer complexes were tethered on polymer and silica supports through amide or ether linkages and applied in the Heck reaction of iodobenzene and n-butylacrylate. ${ }^{[26]}$ Brookhart et al. reported the immobilization of $\mathrm{PCP}$ and $\mathrm{POCOP}$ iridium pincer complexes for transfer dehydrogenation of alkanes on different types of solid supports using three approaches: covalent attachment of phenoxide functionalized iridium pincer to a Merrifield's resin with the chlorobenzyl moieties, covalent bonding of iridium pincers with a pendant alkoxysilane group to silica and adsorption of iridium pincers containing basic functional groups on $\gamma-\mathrm{Al}_{2} \mathrm{O}_{3}$ through a Lewis acid/Lewis base interactions. ${ }^{[27]}$ Goldman et. al. demonstrated the immobilization of bisphosphinite-tert-butyl-irridium pincer complexes on $\gamma-\mathrm{Al}_{2} \mathrm{O}_{3}$ by two methods: covalent attachment of trimethoxysilyl substituted iridium pincers with hydroxyl-functionalized $\mathrm{Al}_{2} \mathrm{O}_{3}$ and binding of para-functionalized POCOP iridium pincers to a coordinately-unsaturated surface Al site in $\mathrm{Al}_{2} \mathrm{O}_{3}{ }^{[28]}$ The dihydride pincer complex [ $\left.\mathrm{IrH}_{2}(\mathrm{POCOP})\right]$ was also anchored on a mesoporous silica (SBA-15) by reaction of hydride with surface silanol groups and utilized as a heterogeneous catalyst for alkene hydrogenation reactions. ${ }^{[29]} \mathrm{Pd}(\mathrm{II})-\mathrm{SCS}$ pincer complexes were covalently immobilized on porous silica, poly(norborene) and cross-linked Merrifield resin supports by C.W. Jones et al. and applied in the Heck reaction. ${ }^{[30-31]}$ G. van Koten et al. reported the anchoring of PCP and SCS palladium pincer complexes on ordered mesoporous silicas through a carbamate linkage between para-trialkoxysilane-functionalized palladium pincers and silica using a grafting process, and utilized the supported catalysts in $\mathrm{C}-\mathrm{C}$ bond formation 
reactions. ${ }^{[23]} \mathrm{NCN}$-pincer palladium and platinum complexes were also tethered to silica for applications as Lewis acid catalysts. ${ }^{[24]}$

Most of the recent reports on the immobilization of pincer complexes require parafunctionality on the preassembled pincer complex to anchor them to the solid supports. Here we report a method that does not require the introduction of para-functionality in the pincer structure and provides a basic surface that can act as a co-catalyst for reactions requiring base.

Several important applications of pincer catalysts require a basic environment or deprotonation to activate the catalyst or substrate. For example, the RuPNN and RuPNP catalyzed dehydrogenative coupling reactions developed by Milstein require deprotonation of the pincer arm to generate the active catalyst. ${ }^{[32 \mathrm{a}]}$ More recently, an FePNP complex has been shown to reduce $\mathrm{CO}_{2}$ to formate at low pressures and also requires base. ${ }^{[32 \mathrm{~b}]}$ The PNP pincer, $\operatorname{Ir}(\mathrm{H})_{3}(2,6-$ $\left.\left({ }^{\mathrm{i}} \mathrm{Pr}_{2} \mathrm{P}\right)_{2}\right) \mathrm{NC}_{5} \mathrm{H}_{3}$ has been shown to be a highly efficient catalyst for reduction of $\mathrm{CO}_{2}$ to formate and requires a $10 \%$ aqueous $\mathrm{KOH} / \mathrm{THF}$ solution. ${ }^{[33]}$ Similarly, the nickel PONOP pincer, $\left.\mathrm{NiH}\left(2,6-\left({ }^{\mathrm{i}} \mathrm{Pr}_{2} \mathrm{PO}\right)_{2}\right) \mathrm{NC}_{5} \mathrm{H}_{3}\right)$ has been shown to be an effective hydrosilation catalyst in the presence of aqueous base. ${ }^{[34]}$ Both of these systems would benefit from elimination of the basic co-reagents by using a surface that could provide the required base. For $\mathrm{CO}_{2}$ reduction water would still be required. There are also a variety of $\mathrm{Pd}(\mathrm{PCP})$ and $\mathrm{Pd}(\mathrm{POCOP})$ pincer complexes that have been applied to $\mathrm{C}-\mathrm{C}$ coupling reactions. On reaction with base, however, many of these release $\operatorname{Pd}(0)$ nanoparticles on reaction with base and would not be suitable for immobilization on surfaces for multiple cycles. ${ }^{[35]}$ On the other hand, there are many reaction types, including aldol-type condensations with electrophiles that do require base using PCP and POCOP frameworks. ${ }^{[35]}$ Thus, there is a large class of pincer-catalyzed reactions that would benefit from a basic surface. 
The silica polyamine composites (SPC) are organic-inorganic hybrid composite materials that have been commercially developed and have been used industrially for applications in the recovery and removal of transition metals, precious metals, and mercury from diverse waste streams and mining leaches (Scheme 2). ${ }^{[36-39]}$
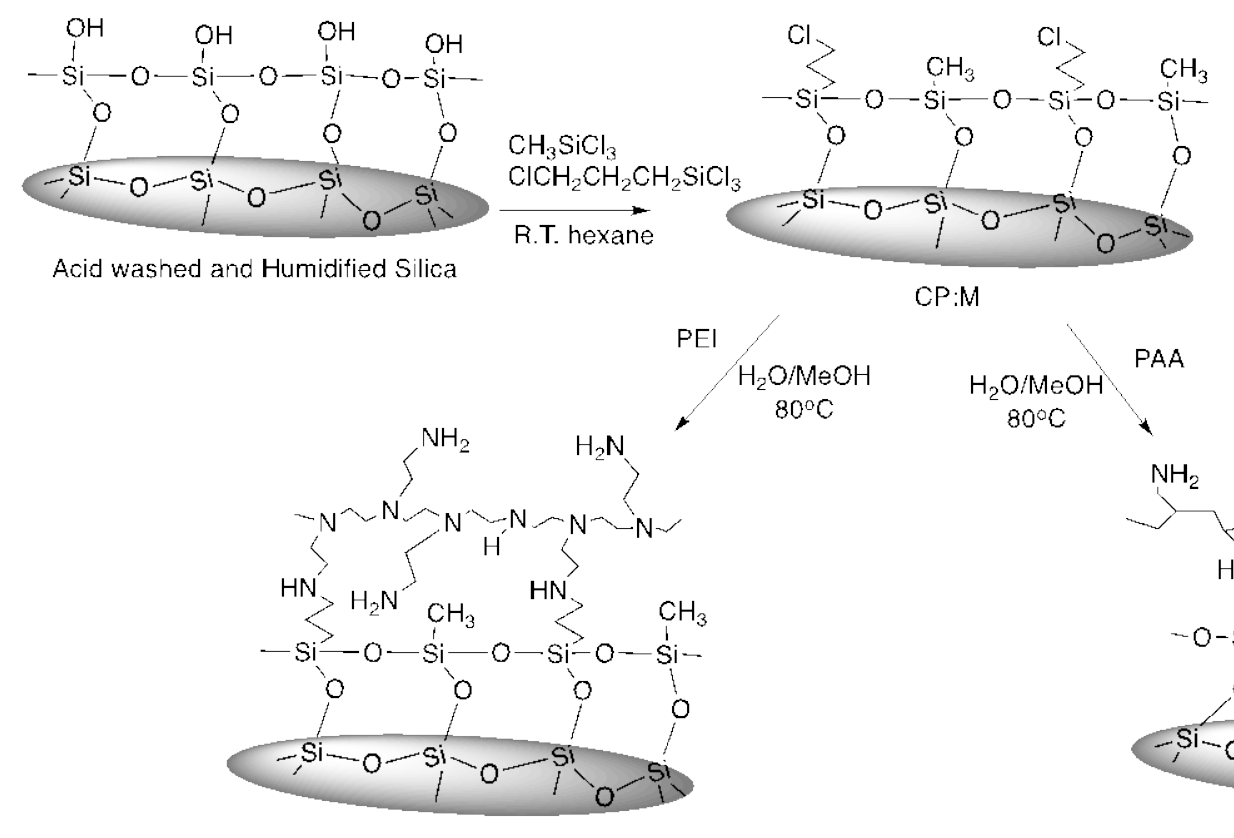

WP-1

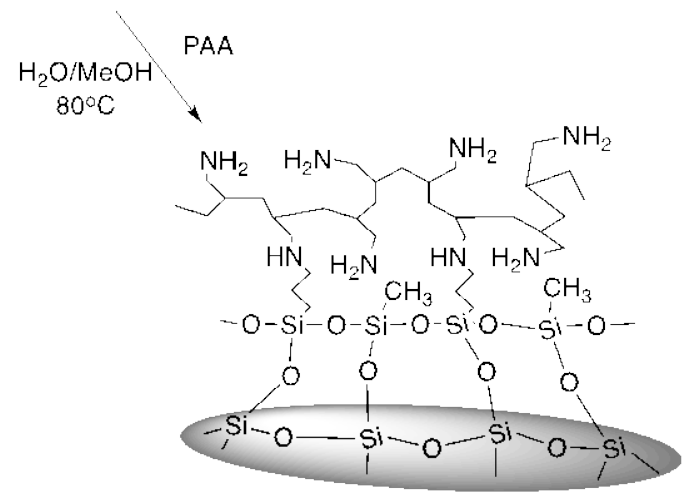

$\mathrm{BP}-1$

Scheme 2. Synthesis of silica polyamine composites

The SPC offer the high ligand loading of polymeric supports with the greater porosity and matrix rigidity of amorphous silica. ${ }^{[39]}$ The SPC yields a silica gel-polyamine surface that can be used as a chelating agent (Scheme 2). The polyamine is covalently bound at multiple points to the silane layer providing additional stability ${ }^{[37]}$ and can be further modified with ligands that make them selective for a given metal or group of metals. ${ }^{[39]}$ These SPC materials do not shrink or swell and can tolerate temperatures up to $200^{\circ} \mathrm{C}$, and have been shown to have long, usable lifetimes. ${ }^{[39]}$ 
The performance of catalysts in heterogeneous systems greatly depends on the nature of the support surface. ${ }^{[40-41]}$ The surface of silica polyamine composites could alter the electronic properties of the catalytically active species or complexes bound to it and could also control molecular access to the active sites of the catalysts in heterogeneous systems in a different way than simple oxide or polystyrene supports. For example, the unmodified amines offer the opportunity to act as base co-catalysts and permit variations in surface $\mathrm{pH}$ (Zeta potential). Recently, we reported the successful use of rhodium, palladium and ruthenium salts immobilized on the SPC surface for selective hydrogenation of olefins and the selective oxidation of phenol to catechol. ${ }^{[42]}$ These studies required thermal stability of the SPCs and this has been confirmed by DTG analysis. ${ }^{[43]}$ In addition, a series of luminescent ruthenium complexes with various types of ligands have also been successfully immobilized on SPC. ${ }^{[14]}$ Given the ease of modification of the SPC amine surface with aromatic ligands using the Mannich Reaction without prior parasubstitution, ${ }^{[38,44]}$ and its ability to provide a basic surface for bifunctional catalysis, SPC would appear to be a suitable candidate for the immobilization of metal pincer complexes.

An attractive multi-dentate nitrogen-phosphorus pincer ligand for the purposes of immobilization on the SPC surface is 2,6-bis(di-tert-butylphosphinito)pyridine (PONOP, Scheme 1). The phosphinite ligand in this system is relatively air-stable and can be easily synthesized prior to immobilization and also after (vide infra). This flexibility offers the opportunity try different routes to immobilization of the pincer ligand. Herein we report three methods for loading and synthesizing the transition metal PONOP pincer complexes on SPC with the goal of evaluating the best pathway for immobilization. 


\section{Experimental}

\subsection{General methods and materials}

The SPC referred to as BP-1, was synthesized using poly(allylamine) (MW $=11-15 \mathrm{Kg}$, Nitobo Buseki, Japan) and has been commercialized as a metal sequestering material for the mining and remediation industries (Scheme 2). ${ }^{[36-39]}$ 2,6-bis(di-tert-butylphosphinito)pyridine (PONOP) was synthesized according to the reported literature procedure. ${ }^{[45]}$ Solvents used were reagent grade. Tetrahydrofuran was distilled from benzophenone ketyl and methylene chloride and acetonitrile were distilled from calcium hydride. 2,6-dihydroxy pyridine hydrochloride (Sigma Aldrich) and $\left(\mathrm{PPh}_{3}\right)_{3} \mathrm{Ru}(\mathrm{H})(\mathrm{CO}) \mathrm{Cl}, \mathrm{NiCl}_{2} \cdot 6 \mathrm{H}_{2} \mathrm{O}$ and $\left(\mathrm{PPh}_{3}\right)_{3} \mathrm{RhCl}$ were purchased from Strem Chemicals, USA. $\mathrm{PdCl}_{2}\left(\mathrm{CH}_{3} \mathrm{CN}\right)_{2}$ was synthesized by a previously reported procedure. ${ }^{[46-}$ 47] Elemental analysis $(\mathrm{C}, \mathrm{H}, \mathrm{N}, \mathrm{P}$ and $\mathrm{Cl})$ were performed by Galbraith Laboratories, Inc, Knoxville, Tennessee, USA. Solid-state CPMAS ${ }^{13} \mathrm{C}$ and ${ }^{31} \mathrm{P}$ NMR were obtained on a Varian NMR Systems $500 \mathrm{MHz}$ spectrometer at 125 and $206 \mathrm{MHz}$ respectively, with spinning speeds of $7-10 \mathrm{KHz} \cdot{ }^{13} \mathrm{C}$ and ${ }^{31} \mathrm{P}$ chemical shifts are reported relative to external tetramethylsilane and phosphoric acid respectively. Solution ${ }^{1} \mathrm{H}$ and ${ }^{31} \mathrm{P}$ NMR were obtained on Varian 500 NMR systems spectrometer at 500 and $206 \mathrm{MHz}$ or a Bruker Avance spectrometer at 400 and 169 $\mathrm{MHz}$ respectively. Infrared spectra were recorded as $\mathrm{KBr}$ pellets on a Thermo-Nicolet $633 \mathrm{FT}$ IR spectrometer. Loading of the metals on BP-1was determined by digesting the composite samples with the mixture of conc. $\mathrm{HCl}$ and conc. $\mathrm{HNO}_{3}$ mixtures $(6: 1)^{[14]}$ and the metal concentration in the digest was determined by Atomic Absorption (AA Spectrometer S Series, Thermoeletronic Corporation, USA). All reactions were carried out under a dry nitrogen atmosphere using standard Schlenk techniques. 
2.2. Immobilization of $\mathrm{M}(\mathrm{PONOP})$ pincer complexes on BP-1 by direct reaction with the preformed complex (method 1) $(\mathrm{M}=\mathrm{Ru}, \mathrm{Pd}, \mathrm{Ni}, \mathrm{Rh})$

$5 \mathrm{~g}$ of BP-1 (containing $1.6 \mathrm{mmol} \mathrm{N} / \mathrm{g}$ ) was mixed with a reagent solution of $25 \mathrm{~mL}$ aqueous $\mathrm{HCHO}(38 \%, 345 \mathrm{mmol})$ and $0.5 \mathrm{~mL}$ glacial acetic acid $(17.4 \mathrm{M}, 8.74 \mathrm{mmol})$ in a 250 $\mathrm{mL}$ flask equipped with an overhead stirrer. The suspension was stirred for $3-4 \mathrm{~h}$ at room temperature yielding the surface-bound imine intermediate. The resulting composite was filtered and then washed several times with $95 \%$ ethanol, filtered, and then dried under vacuum overnight (yield: $5.16 \mathrm{~g}$ ). This dried intermediate composite product was used for immobilization of each of the following complexes on BP-1.

\subsubsection{Immobilization of (PONOP)RuHCl(CO)on BP-1}

$500 \mathrm{mg}(0.885 \mathrm{mmol})$ of (PONOP)RuHCl$(\mathrm{CO})^{[48]}$ and $25 \mathrm{~mL}$ of distilled $\mathrm{THF}$ were added to $5 \mathrm{~g}$ of dried imine intermediate in a three-necked round bottom flask equipped with an overhead stirrer and a condenser. The mixture was degassed by applied vacuum (30 $\mathrm{mmHg})$. The temperature of the mixture was raised to $70^{\circ} \mathrm{C}$ and the reaction mixture was refluxed overnight with stirring under $\mathrm{N}_{2}$. The composite product was then filtered and washed four times with THF and four times with $\mathrm{CH}_{2} \mathrm{Cl}_{2}$ and then dried overnight under high vacuum yielding $5.34 \mathrm{~g}$ of $\mathrm{BP}$ 1-(PONOP)RuHCl(CO)(1) product. IR spectra (KBr pellet): $1952 \mathrm{~cm}^{-1}$ (s) (vCO). Elemental analysis and NMR data are given in Table $1 \mathrm{~A}$.

\subsubsection{Immobilization of $\mathrm{M}(\mathrm{PONOP})$ complexes on $\mathrm{BP}-1(\mathrm{M}=\mathrm{Pd}, \mathrm{Ni}, \mathrm{Rh})$}

The procedure described above was used for the immobilization of the $\mathrm{Pd}$ and $\mathrm{Ni}$ complexes using $500 \mathrm{mg}$ of $[(\mathrm{PONOP}) \mathrm{PdCl}] \mathrm{Cl}^{[47]}$ and $[(\mathrm{PONOP}) \mathrm{NiCl}] \mathrm{Cl}^{[47]}$ respectively. Conditions and solvents are shown in Scheme 3 and the yields for the resulting composites, BP- 
1-[(PONOP)PdCl]Cl(2), BP-1-[(PONOP)NiCl]Cl(3) were $5.41 \mathrm{~g}$ and $5.17 \mathrm{~g}$ for the $\mathrm{Pd}$ and Nickel respectively. Elemental analysis and NMR data are given in Table 1B and 1C.

(PONOP)RhCl was previously reported ${ }^{[49]}$ but was synthesized here by a different route; the reaction of PONOP (50 mg, $0.125 \mathrm{mmol})$ with $\mathrm{Rh}\left(\mathrm{PPh}_{3}\right)_{3} \mathrm{Cl}(116 \mathrm{mg}, 0.125 \mathrm{mmol})$ in dried $\mathrm{C}_{6} \mathrm{H}_{6}$, refluxed overnight under $\mathrm{N}_{2}$ (yield: $46 \mathrm{mg}, 0.086 \mathrm{mmol} 69 \%$ ). ${ }^{1} \mathrm{H} \mathrm{NMR}$ (500 MHz, $\left.\mathrm{CD}_{2} \mathrm{Cl}_{2}\right): \delta 7.58\left(\mathrm{t}, J_{\mathrm{H}-\mathrm{H}}=5.0 \mathrm{~Hz}, 1 \mathrm{H}, p-\mathrm{C}_{5} \mathrm{H}_{3} \mathrm{~N}\right), 7.12\left(\mathrm{~d}, J_{\mathrm{H}-\mathrm{H}}=5.0 \mathrm{~Hz}, 2 \mathrm{H}, m-\mathrm{C}_{5} \mathrm{H}_{3} \mathrm{~N}\right), 1.34(\mathrm{vt}$, $\left.J_{\mathrm{P}-\mathrm{H}}=15.0 \mathrm{~Hz}, 36 \mathrm{H}, \mathrm{P}-\mathrm{C}\left(\mathrm{CH}_{3}\right)_{3}\right) .{ }^{31} \mathrm{P}\left\{{ }^{1} \mathrm{H}\right\} \mathrm{NMR}\left(500 \mathrm{MHz}, \mathrm{CD}_{2} \mathrm{Cl}_{2}\right): \delta 197.8\left(\mathrm{~d}, J_{\mathrm{Rh}-\mathrm{P}}=370 \mathrm{~Hz}\right)$, $500 \mathrm{mg}$ of (PONOP)RhCl made by this route using the conditions shown in Scheme 3 yielded $5.21 \mathrm{~g}$ of $\mathrm{BP}-1(\mathrm{PONOP}) \mathrm{RhCl}$ (4). Solid-state ${ }^{13} \mathrm{C}$ and ${ }^{31} \mathrm{P} \mathrm{NMR}$ data and the elemental analysis data, are given in Table 1D.

\subsection{Immobilization of $\mathrm{M}(\mathrm{PONOP})$ pincers on BP-1 by ligand grafting followed by addition of metal complexes (method 2)}

\subsubsection{Immobilization of PONOP on BP-1}

Using the method for making the imine intermediate given in section $2.2,500 \mathrm{mg}(1.25$ $\mathrm{mmol}$ ) of PONOP ${ }^{[48]}$ in $30 \mathrm{~mL}$ distilled THF was added to $5 \mathrm{~g}$ of the imine intermediate and the mixture was degassed for 10 minutes by applied vacuum. The mixture was refluxed overnight with stirring under $\mathrm{N}_{2}$. The resulting composite product was cooled and then filtered and washed five times with distilled THF and four times with $\mathrm{CH}_{2} \mathrm{Cl}_{2}$ and dried overnight under high vacuum (yield, 5.23 g). Elemental analysis: C $12.71 \%$, H 2.50\%,N 2.46\%, P 0.497\%. Solid-state CPMAS ${ }^{13} \mathrm{C}$ NMR, $\delta: 163$ (pyridine), $47.9\left(\mathrm{CH}_{2}\right.$ polyamine), 33.3 (tert-butyl), 23.4 (tert-butyl), -6.5 $\left(\mathrm{Si}_{-} \mathrm{CH}_{3}\right) . \mathrm{CPMAS}^{31} \mathrm{P} \mathrm{NMR}: \delta$ 52.4. 


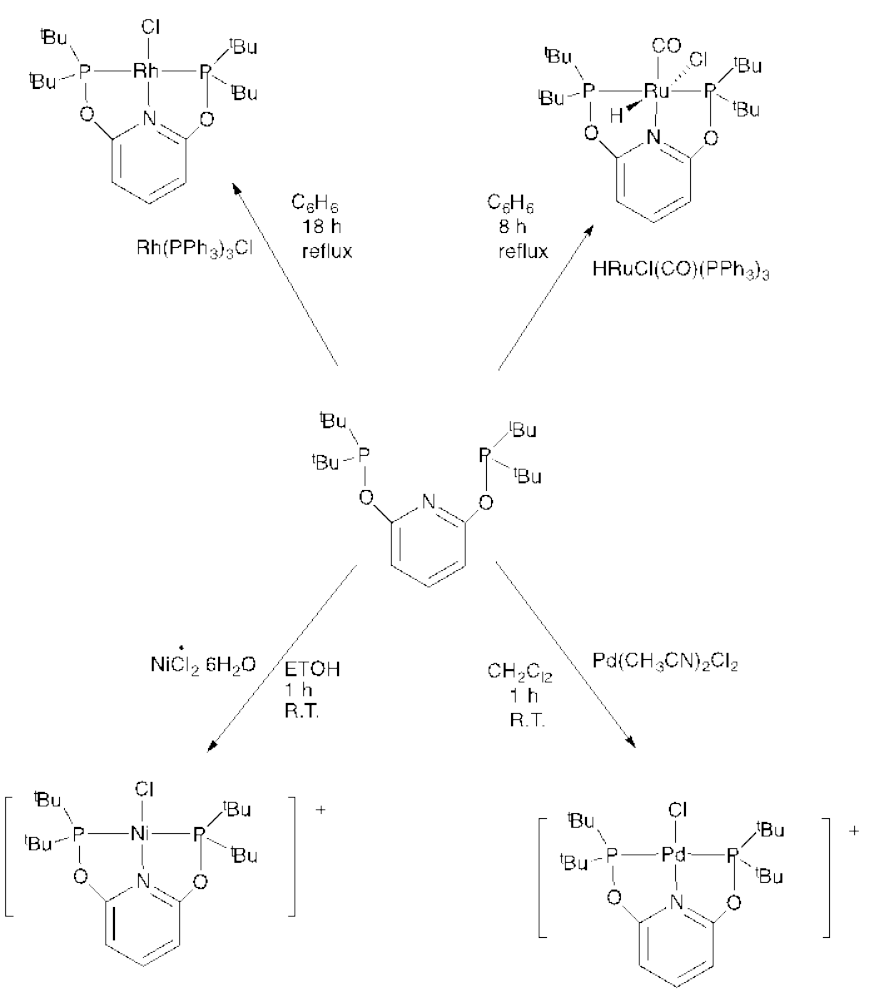

Scheme 3: Synthesis of (PONOP)Ru(H)Cl(CO), [(PONOP)PdCl]Cl, [(PONOP)NiCl]Cl and (PONOP)RhCl.

\subsubsection{Preparation M(PONOP) pincers on BP-1 loaded with PONOP by method 2}

$500 \mathrm{mg}(0.525 \mathrm{mmol})$ of $\left(\mathrm{PPh}_{3}\right)_{3} \mathrm{RuHCl}(\mathrm{CO})$ was combined with $5 \mathrm{~g}$ of BP-1 loaded with PONOP in a three-necked flask equipped with overhead stirrer and a condenser. $25 \mathrm{~mL}$ of distilled THF was added and the mixture was degassed for 10 minutes by applied vacuum. The reaction was refluxed under $\mathrm{N}_{2}$ for overnight. The resulting composite BP-1(PONOP)RuHCl(CO)(1), product was cooled, then filtered and washed five times with THF and four times with $\mathrm{CH}_{2} \mathrm{Cl}_{2}$ and then dried overnight under high vacuum (yield, $5.72 \mathrm{~g}$ ).

The procedure was repeated for the synthesis of $\mathrm{BP}-1-[(\mathrm{PONOP}) \mathrm{PdCl}] \mathrm{Cl}(2), \mathrm{BP}-1$ $[(\mathrm{PONOP}) \mathrm{NiCl}] \mathrm{Cl}(3)$ and $\mathrm{BP}-1-(\mathrm{PONOP}) \mathrm{RhCl}(4)$ by method 2 with the addition of the respective metal compounds, $\mathrm{PdCl}_{2}\left(\mathrm{CH}_{3} \mathrm{CN}\right)_{2}, \mathrm{NiCl}_{2} \cdot 6 \mathrm{H}_{2} \mathrm{O}$ and $\left(\mathrm{PPh}_{3}\right)_{3} \mathrm{RhCl}$ and using the 
solvents, distilled $\mathrm{CH}_{2} \mathrm{Cl}_{2}$, absolute EtOH and $\mathrm{C}_{6} \mathrm{H}_{6}$ respectively (Scheme 3). A similar procedure was followed to separate and dried each of the composite products (yield: $5.58 \mathrm{~g}, 5.45 \mathrm{~g}$ and 5.41g respectively). Solid-state ${ }^{13} \mathrm{C}$ and ${ }^{31} \mathrm{P}$ NMR data elemental analysis data are given in Table 1A-1D.

\subsection{Immobilization of $\mathrm{M}(\mathrm{PONOP})$ pincers on BP-1 by stepwise construction of the PONOP on BP-1 followed by addition of metal complexes (method 3)}

\subsubsection{Stepwise construction of PONOP on BP-1}

To $5 \mathrm{~g}$ of the imine intermediate prepared according to section 2.2 was added $1.2 \mathrm{~g}(10.81$ mmol) of 2,6-dihydroxy pyridine [obtained by the addition of $\mathrm{NaOH}(328 \mathrm{mg}, 8.2 \mathrm{mmol})$ to2,6dihydroxy pyridine hydrochloride $(1.21 \mathrm{~g}, 8.2 \mathrm{mmol})$ in $25 \mathrm{~mL}$ absolute EtOH adjusted to $\mathrm{pH}=9$ ]. $30 \mathrm{~mL}$ of absolute $\mathrm{EtOH}$ was added and the mixture was degassed by applied vacuum for 10 minutes. The temperature of the mixture was raised to $65-70{ }^{0} \mathrm{C}$ and reaction was carried out for 24 hours under $\mathrm{N}_{2}$. The solvent was then removed and the resulting composite product was washed four times with absolute EtOH, three times with distilled THF, three times with $\mathrm{CH}_{2} \mathrm{Cl}_{2}$ and three times with $\mathrm{CH}_{3} \mathrm{OH}$ and hence dried under vacuum. This dried composite product was then transferred to a three-necked round bottom flask equipped with an overhead stirrer. $30 \mathrm{~mL}$ of distilled THF was added and the mixture was degassed by an applied vacuum. $2.85 \mathrm{~mL}$ (16 mmol) of N,N-diisopropylethyleneamine (DIEPA) and $3.1 \mathrm{~mL}(16 \mathrm{mmol})$ of $\left({ }^{\mathrm{t}} \mathrm{Bu}\right)_{2} \mathrm{PCl}$ were mixed with the composite mixture in $\mathrm{THF}$ under $\mathrm{N}_{2}$. The mixture was then stirred for $24 \mathrm{~h}$ at room temperature under $\mathrm{N}_{2}$ to complete the reaction. Solvent was then removed from the final composite product and was washed four times with $\mathrm{CH}_{2} \mathrm{Cl}_{2}$, four times with THF and four times with $\mathrm{EtOH}$ and finally dried overnight under high vacuum (yield: $5.19 \mathrm{~g}$ ). Elemental analysis: C 
$12.54 \%$, H 2.40\%, N 2.38\%, P 0.485\%. Solid-state CPMAS ${ }^{13}$ C NMR, $\delta: 163$ (pyridine), 47.9 ( $\mathrm{CH}_{2}$ polyamine), 33.3 (tert-butyl), 23.4 (tert-butyl), - $6.5\left(\mathrm{Si}_{-} \mathrm{CH}_{3}\right)$. CPMAS ${ }^{31} \mathrm{P}$ NMR: $\delta 52.4$

\subsubsection{Immobilization $\mathrm{M}(\mathrm{PONOP})$ pincerson $\mathrm{BP}-1$ by addition of metal compounds to pre- constructed PONOP (method 3)}

Each of the four pincer immobilized complexes BP-1-(PONOP)RuHCl(CO)(1),BP-1$[(\mathrm{PONOP}) \mathrm{PdCl}] \mathrm{Cl}(\mathbf{2}), \mathrm{BP}-1-[(\mathrm{PONOP}) \mathrm{NiCl}] \mathrm{Cl}(3)$ and $\mathrm{BP}-1-(\mathrm{PONOP}) \mathrm{RhCl}(4)$ were made on BP-1 following the same procedure as in section 2.3.2. Yields of the composite products were $5.67 \mathrm{~g}, 5.48 \mathrm{~g}, 5.36 \mathrm{~g}$ and $5.29 \mathrm{~g}$ respectively. Elemental analysis, solid-state ${ }^{13} \mathrm{C}$ and ${ }^{31} \mathrm{P}$ NMR data are given in Table 1A-1D.

\subsection{Experimental procedure for the reaction between n-butylamine and PONOP in solution}

$200 \mu \mathrm{L}(2 \mathrm{mmol})$ of $\mathrm{n}$-butylamine was added to $200 \mu \mathrm{L}(38 \%, 2 \mathrm{mmol})$ of $\mathrm{HCHO}$ solution. $20 \mu \mathrm{L}(0.35 \mathrm{mmol})$ of glacial acetic acid $(17.4 \mathrm{M})$ was added and the reaction mixture was stirred overnight at room temperature under $\mathrm{N}_{2}$. The resulting imine intermediate was extracted with distilled $\mathrm{CH}_{2} \mathrm{Cl}_{2}$ and then anhydrous $\mathrm{Na}_{2} \mathrm{SO}_{4}$ was added to remove any trace $\mathrm{H}_{2} \mathrm{O}$. Solvent was then removed and the product was dried under high vacuum. $0.8 \mathrm{~g}(2 \mathrm{mmol})$ PONOP was combined with the dried imine intermediate in $8 \mathrm{~mL}$ distilled THF. The reaction was carried out at $60^{\circ} \mathrm{C}$ overnight under $\mathrm{N}_{2}$. Solvent was removed and then the resulting product was dried under high vacuum (yield: $0.58 \mathrm{~g}, 1.19 \mathrm{mmol}, 60 \%) .{ }^{31} \mathrm{P}$ NMR: $\delta 112.46$ (s), $\delta 117.13$ (s, br), and $\delta 118.62(\mathrm{~s}) .{ }^{1} \mathrm{H}$ NMR (two isomers): $\delta 0.74\left(\mathrm{t}, J_{\mathrm{H}-\mathrm{H}}=10.0 \mathrm{~Hz}, 3 \mathrm{H}, \mathrm{CH}_{3}\right), 0.89$ (sextet, $\left.J_{\mathrm{H}-\mathrm{H}}=5.0 \mathrm{~Hz}, 2 \mathrm{H}, \mathrm{CH}_{2}\right), 1.61\left(\right.$ sextet, $\left.J_{\mathrm{H}-\mathrm{H}}=7.0 \mathrm{~Hz}, 2 \mathrm{H}, \mathrm{CH}_{2}\right), 1.24\left(\mathrm{~d}, J_{\mathrm{P}-\mathrm{H}}=15.0 \mathrm{~Hz}\right.$, $\left.36 \mathrm{H}, \mathrm{P}-\mathrm{C}\left(\mathrm{CH}_{3}\right)_{3}\right), 1.89\left(\mathrm{~s}, 36 \mathrm{H}, \mathrm{P}-\mathrm{C}\left(\mathrm{CH}_{3}\right)_{3}\right), 2.26$ (pent, $\left.J_{\mathrm{H}-\mathrm{H}}=5.0 \mathrm{~Hz}, 2 \mathrm{H}, \mathrm{CH}_{2}\right), 2.81$ (pent, $J_{\mathrm{H}-\mathrm{H}}=$ $\left.5.0 \mathrm{~Hz}, 2 \mathrm{H}, \mathrm{CH}_{2}\right), 2.40\left(\mathrm{t}, J_{\mathrm{H}-\mathrm{H}}=7.5 \mathrm{~Hz}, 2 \mathrm{H}, \mathrm{CH}_{2}\right), 2.61\left(\mathrm{t}, J_{\mathrm{H}-\mathrm{H}}=7.5 \mathrm{~Hz}, 2 \mathrm{H}, \mathrm{CH}_{2}\right), 2.98\left(\mathrm{~d}, J_{\mathrm{H}-\mathrm{H}}=\right.$ 
$\left.7.5 \mathrm{~Hz}, 2 \mathrm{H}, \mathrm{CH}_{2}\right), 2.53\left(\mathrm{~s}, 2 \mathrm{H}, \mathrm{CH}_{2}\right), 10.32$ (s, br, 1H, N-H), 8.57 (s, 2H, m-pyridine, paraisomer), 7.56 (s,br, 1H,pyridine,meta-isomer), 7.37 (s,br,1H, pyridine, meta-isomer).

\subsection{Experimental procedure for the reaction between $(\mathrm{PONOP}) \mathrm{RuH}(\mathrm{CO}) \mathrm{Cl}$ and $\mathrm{n}$ -} butylamine in solution

$200 \mu \mathrm{L}(2 \mathrm{mmol})$ of $\mathrm{n}$-butylamine was added to $200 \mu \mathrm{L}(38 \%, 2 \mathrm{mmol})$ of $\mathrm{HCHO}$ solution. $20 \mu \mathrm{L}(0.35 \mathrm{mmol})$ of glacial acetic acid $(17.4 \mathrm{M})$ was added and the reaction mixture was stirred overnight at room temperature under $\mathrm{N}_{2}$. The resulting imine intermediate was extracted with distilled $\mathrm{CH}_{2} \mathrm{Cl}_{2}$ and then anhydrous $\mathrm{Na}_{2} \mathrm{SO}_{4}$ was added to remove any trace $\mathrm{H}_{2} \mathrm{O}$. Solvent was then removed and the product was dried under high vacuum. $1.12 \mathrm{~g}$ ( $2 \mathrm{mmol})$ of (PONOP)RuH(CO)Cl was combined with the dried imine intermediate in $15 \mathrm{~mL}$ distilled THF.

The reaction was carried out at $66^{\circ} \mathrm{C}$ for 24 hours under $\mathrm{N}_{2}$. Solvent was removed and the resulting product was washed with pentane and $\mathrm{CH}_{2} \mathrm{Cl}_{2}$ and then dried under high vacuum (yield: $0.73 \mathrm{~g}, 1.13 \mathrm{mmol}, 57 \%) .{ }^{31} \mathrm{P} \mathrm{NMR}\left(\mathrm{C}_{6} \mathrm{D}_{6}\right): \delta 62.57$ (s), $58.06(\mathrm{~s})$, and 57.43 (s). ${ }^{1} \mathrm{H}$ NMR $\left(\mathrm{C}_{6} \mathrm{D}_{6}\right)$ (two isomers): $\delta 0.77\left(\mathrm{t}, J_{\mathrm{H}-\mathrm{H}}=7.5 \mathrm{~Hz}, 3 \mathrm{H}, \mathrm{CH}_{3}\right), 1.09$ (sextet, $J_{\mathrm{H}-\mathrm{H}}=7.4 \mathrm{~Hz}, 2 \mathrm{H}, \mathrm{CH}_{2}$ ), 3.09 (sextet, $\left.J_{\mathrm{H}-\mathrm{H}}=8.1 \mathrm{~Hz}, 2 \mathrm{H}, \mathrm{CH}_{2}\right), 0.28\left(\mathrm{~s}, 36 \mathrm{H}, \mathrm{P}-\mathrm{C}\left(\mathrm{CH}_{3}\right)_{3}\right), 1.19$ (pent, $J_{\mathrm{H}-\mathrm{H}}=6.8 \mathrm{~Hz}, 2 \mathrm{H}$, $\mathrm{CH}_{2}$ ), 2.45 (pent, $\left.J_{\mathrm{H}-\mathrm{H}}=7.5 \mathrm{~Hz}, 2 \mathrm{H}, \mathrm{CH}_{2}\right), 0.84\left(\mathrm{t}, J_{\mathrm{H}-\mathrm{H}}=7.5 \mathrm{~Hz}, 2 \mathrm{H}, \mathrm{C} H_{2}\right), 1.45\left(\mathrm{~d}, J_{\mathrm{H}-\mathrm{H}}=12.4\right.$ $\mathrm{Hz}, 2 \mathrm{H}, \mathrm{CH}_{2}$ ), 3.52 (s, 2H, $\mathrm{CH}_{2}$ ), 5.48 (s, br, 1H, N-H), 8.02 (s, 2H, m-pyridine, para-isomer), $7.72\left(\mathrm{dd}, J_{\mathrm{H}-\mathrm{H}}=6.6 \mathrm{~Hz}, 2 \mathrm{H}\right.$, pyridine, meta-isomer). IR spectra (ATR): $1942 \mathrm{~cm}^{-1}(\mathrm{~s})(v \mathrm{CO})$, $2036 \mathrm{~cm}^{-1}(\mathrm{~s})(v \mathrm{Ru}-\mathrm{H})$.

2.7. Determination of the metal content of $\mathrm{M}(\mathrm{PONOP})$ pincers on BP-1 by digestion and AAS

Loading of the metals on $\mathrm{BP}-1$ as $\mathrm{M}(\mathrm{PONOP})$ pincers $(\mathrm{M}=\mathrm{Ru}, \mathrm{Pd}, \mathrm{Ni}, \mathrm{Rh})$ by the three methods was determined by digestion of the composites by a previously reported procedure. ${ }^{[14]}$ 
$40 \mathrm{mg}$ of each of the composite samples loaded with metal pincers was heated overnight at 500 ${ }^{0} \mathrm{C}$. The samples were cooled to room temperature and $0.5 \mathrm{~mL}$ of $\mathrm{HF}$ was added into each of them. Then $0.5 \mathrm{~mL}$ of a mixture of conc. $\mathrm{HCl}$ and conc. $\mathrm{HNO}_{3}(6: 1)$ was added. Finally, each of the digest solutions were diluted with deionized water and made up to a total volume of $4.5 \mathrm{~mL}$. Metal concentrations in the digest solutions were determined by Atomic Absorption Spectroscopy after construction of standard calibration curves with absorption ranges of 0.001 to 2, using standard solutions (Fischer Scientific), diluted five times to give the appropriate absorbance. The results obtained in mmol/g of composite are given in Table 2 (calibration curves were made in the following absorbance ranges for $\mathrm{Ru}, 0.001$ to 0.02 ; for $\mathrm{Pd}, 0.5$ to 2 ; for $\mathrm{Ni}, 0.02$ to 0.8 ; for $\mathrm{Rh}, 0.003$ to 0.06 .

\section{Results and discussion}

The PONOP ligand and the PONOP transition metal complexes were synthesized following previously reported literature procedures (Scheme 3 ) ${ }^{[47-48]}$ Three different approaches have been attempted for immobilization of the PONOP pincer transition metal complexes on BP1. The first approach involved direct reaction of the preassembled pincer complexes using a twostep Mannich reaction. In method 2, the preformed PONOP ligand was anchored on BP-1 using the same Mannich procedure followed by addition of the appropriate transition metal compound. In method 3, the PONOP ligand was constructed on BP-1 using three sequential reactions on the composite surface (Scheme 4) and subsequent synthesis of the pincer complex was accomplished by addition of the transition metal compound. Treatment of BP-1 with $38 \%$ aqueous formaldehyde yields the imine-BP-1 intermediate product, which is the electrophile that reacts with the pyridine ring of the PONOP (Schemes $4 \& 5$ ). The metal compounds used were $\left(\mathrm{PPh}_{3}\right)_{3} \mathrm{Ru}(\mathrm{H})(\mathrm{CO}) \mathrm{Cl}, \mathrm{PdCl}_{2}\left(\mathrm{CH}_{3} \mathrm{CN}\right)_{2}, \mathrm{NiCl}_{2} \cdot 6 \mathrm{H}_{2} \mathrm{O}$ and $\left(\mathrm{PPh}_{3}\right)_{3} \mathrm{RhCl}$. The reaction pathways 
for the methods 2 and 3 are illustrated in Schemes 4 and 5. It is not possible to determine the site of electrophilic aromatic substitution on the PONOP ligand from the CPMAS NMR data. Electronic factors would favor substitution meta- to $\mathrm{N}$ in the pyridine ring while steric factors would favor para-substitution. Modeling of the reaction in solution indicates a mixture of both (vide infra).

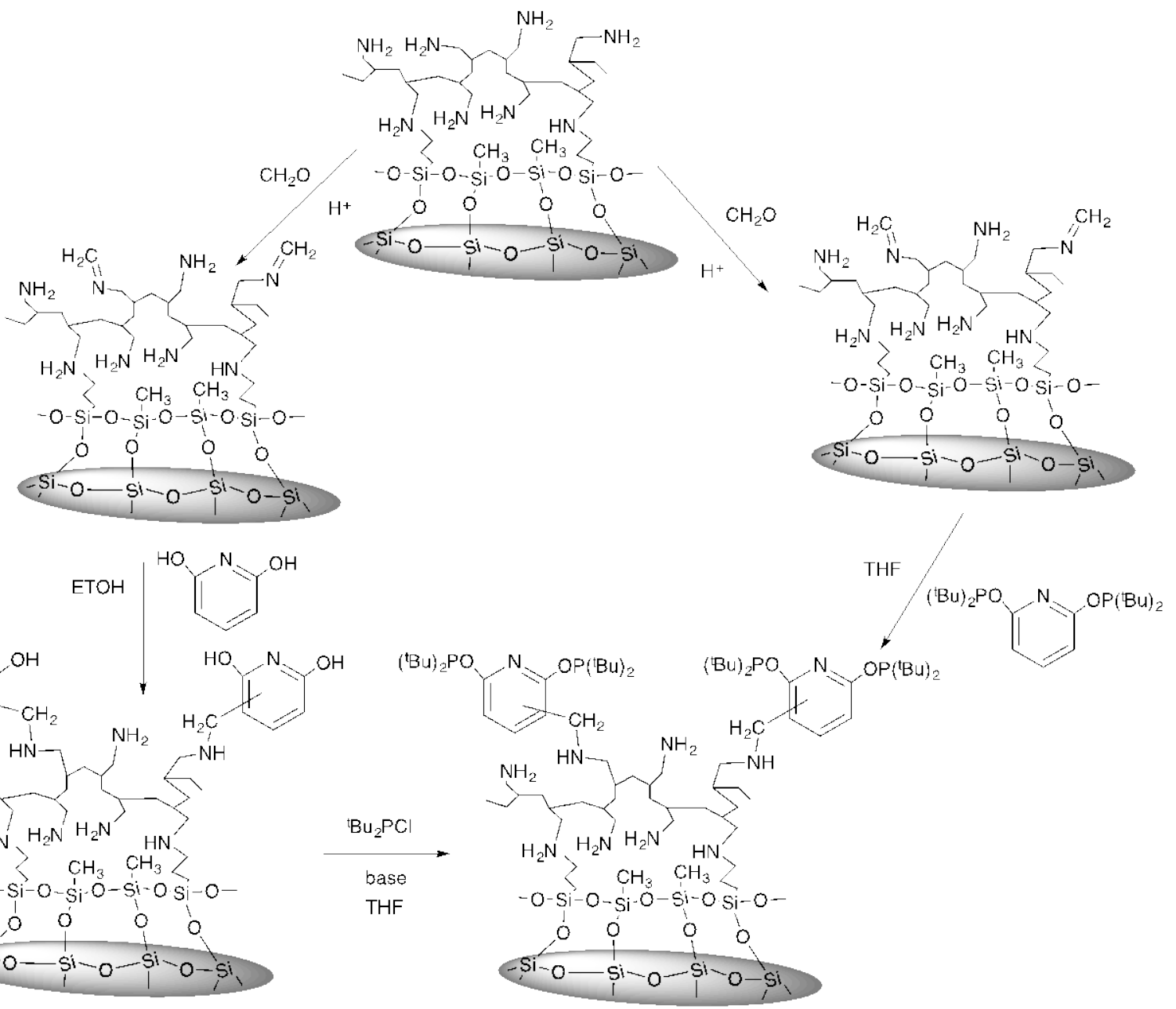

Scheme 4. The two methods for immobilization of the PONOP ligand on BP-1 


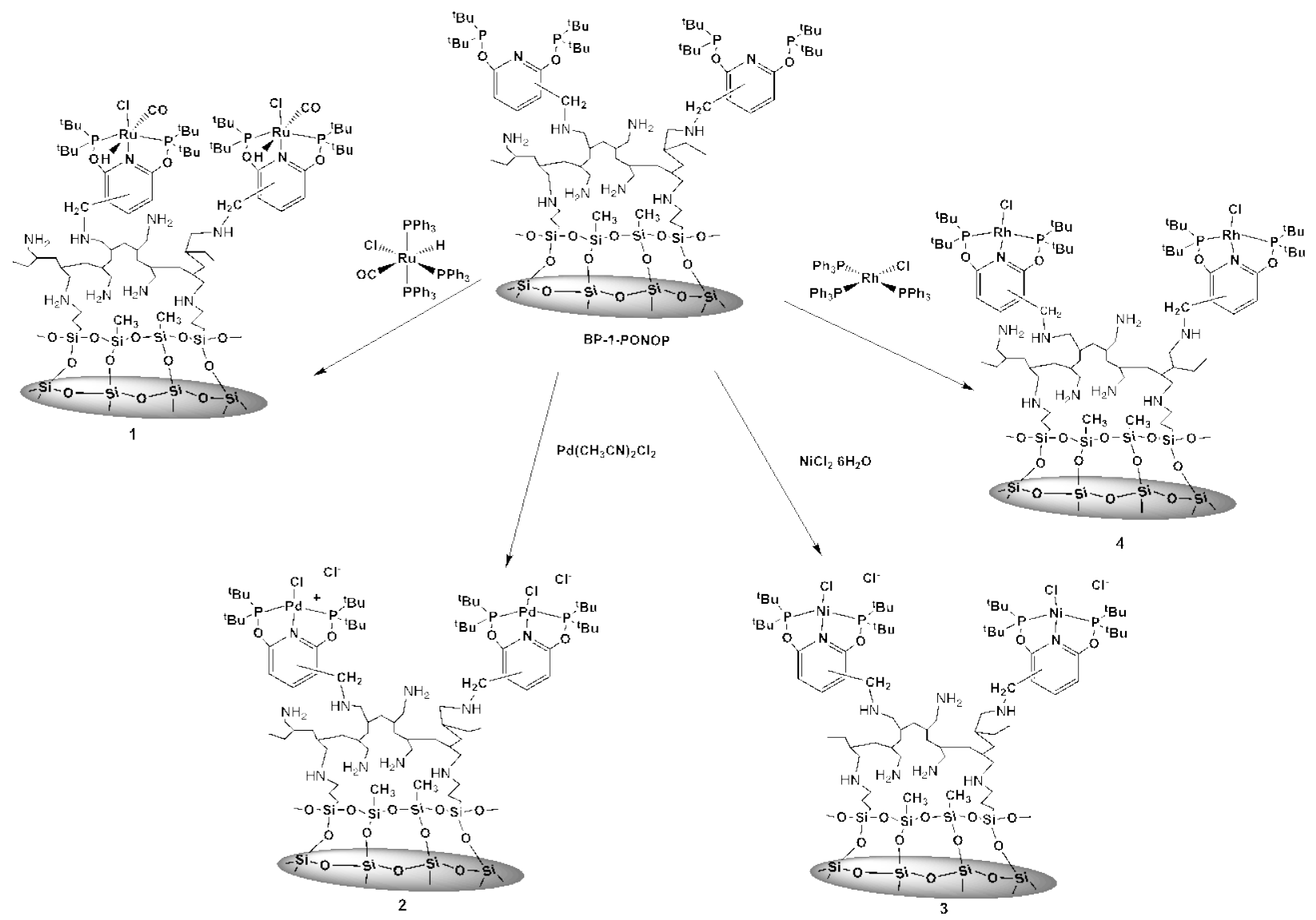

Scheme 5. Proposed structures for the immobilized PONOP pincer ligand complexes (conditions for addition of the metal compounds were the same as shown in Scheme 3)

\subsection{Characterization of the immobilized PONOP pincer ligand and its complexes}

Anchoring of the PONOP ligand on BP-1 by methods $2 \& 3$ is supported by the observation of resonance for the tert-butyl carbons at $\delta 33.3$ and 23.4 and the pyridine carbons at $\delta 163$ in the solid-state CPMAS ${ }^{13} \mathrm{C}$ NMR spectra. A broad resonance at $\delta 52.4$ in the solid-state ${ }^{31} \mathrm{P}$ NMR spectra is also consistent with the loading of the ligand on BP-1. It should be noted that the resonances observed for CPMAS ${ }^{31} \mathrm{P}$ NMR spectra for the PONOP ligand on BP-1 are shifted significantly up-field with respect to those observed in solution phase $(\delta 151.3) .{ }^{[45]}$ This might be due to the electronic environment and nature of the surface of SPC-BP-1. Previous studies also showed significant up-field chemical shifts for the pincer ligands and their 
complexes upon immobilization on to solid supports. ${ }^{[28]}$ However, CPMAS ${ }^{13} \mathrm{C}$ resonances of the immobilized PONOP ligand and their complexes showed good agreement with the resonances found in solution ( $\delta 163.1$, pyridine $; \delta 35.5$, tert-butyl carbons) ${ }^{[47-49]}$ Solid-state CPMAS ${ }^{13} \mathrm{C}$ NMR spectra of the ligand and the four complexes on BP-1 displayed additional resonances at $\delta-4$ to -6 due to the methyl groups bound to Si from the methyl trichlorosilane used in the silanization of the starting silica gel. The resonances in the range of $\delta 40-50$ are assigned to the $\mathrm{CH}$ and $\mathrm{CH}_{2}$ - groups of poly(allylamine) and the propyl anchors bound to the starting BP-1. ${ }^{[36]}$ The increase in $\mathrm{N}$ content after correction for the weight gain by methods 2 and 3 was too small to allow an accurate determination to the $\mathrm{P} / \mathrm{N}$ ratio for the immobilized ligand.

The imine-functionalized BP-1 intermediate showed a characteristic $v_{\mathrm{C}=\mathrm{N}}$ at $\sim 1663 \mathrm{~cm}^{-1}$ which is not observed in the spectra of pristine BP-1. Upon reaction with the PONOP ligand or the corresponding pincer complexes only a small decrease in intensity of this resonance is observed indicating only partial loading of the complexes. This is also supported by the results of the metal digestion study that indicate low loading of the complexes (Table 2). IR spectra of (PONOP)RuHCl(CO) immobilized on BP-1 showed a metal carbonyl stretch at $1952 \mathrm{~cm}^{-1}$ for all three synthetic methods. Given that the carbonyl stretch for this complex in solution is $1932 \mathrm{~cm}^{-1}$ indicates that there is a change in the electronic environment at the metal centre of the complex upon attachment on BP-1. ${ }^{[48]}$ This large change in the CO stretch could be due to substituent effects (vide infra) and/or the formation of hydrogen bonds between the hydride in this complex and an amine lone pair an amine hydrogen. There is considerable evidence for both of these interactions in the solid-state structures of amine-substituted carbonyl hydride complexes. ${ }^{50}$ However, it is difficult to predict the magnitude and direction of the frequency change, especially if both interactions are present. Observation of a CO stretch does support the formation of BP-1- 
(PONOP)RuHCl(CO)(1) on BP-1 by the three methods. The IR spectra of the other three supported PONOP metal complexes (2), (3) \& (4) were not informative except for the appearance of small increase in the intensities of the band at $\sim 2930 \mathrm{~cm}^{-1}$ assignable to the C-H stretches and the observed residual imine at $\sim 1663 \mathrm{~cm}^{-1}$.

The CPMAS ${ }^{13} \mathrm{C}$ and ${ }^{31} \mathrm{P}$ NMR of complexes 1-4 (Scheme 5) along with their elemental analyses are shown Tables 1A -1D. Representative spectra are given in Figures 1S-10S in the Supporting Information. For 1 made by method 1, the tert-butyl groups appear as relatively sharp resonances at $\delta 33.8$ and 23.9 and the pyridine carbons appear as a broad resonance at $\delta 163.5$ in solid-state CPMAS ${ }^{13} \mathrm{C}$ NMR spectra. The IR data indicates that the unreacted $\mathrm{C}=\mathrm{N}$ bond survives the conditions for binding the pincer ligand to the surface. The chemical shift of this bond is in $\sim \delta 161$, and is observed prior to reaction with the pincer or pincer ligand complex but overlaps with the broad pyridine resonance. Interestingly, all the ${ }^{13} \mathrm{C} N \mathrm{NR}$ spectra of the surface bound pincers show a sharp component at $\sim \delta 161$ suggesting that the unreacted imine persists, consistent, with the IR data (see Figures $1 \mathrm{~S}, 3 \mathrm{~S}, 5 \mathrm{~S}, 7 \mathrm{~S}, 9 \mathrm{~S}$ ). The $\mathrm{CH}_{2}$ groups attached to the amine of the polymer appear as relatively sharp resonances centered at $\delta$ 48.5. Solid-state CPMAS ${ }^{31} \mathrm{P}$ NMR of composite 1 exhibited a resonance at $\delta 58$. Taken together these data confirm the presence of (PONOP)RuHCl(CO) on BP-1. The composite $\mathbf{1}$, made by methods 2 and 3, showed the same overall pattern of resonances as for method 1 but had slightly different chemical shifts for tert-butyl groups. However, an additional resonance at $\delta 129.7$ in the CPMAS ${ }^{13} \mathrm{C}$ spectrum of composite 1 is attributed to triphenylphosphine and a resonance at $\delta 44.4$ in the CPMAS ${ }^{31} \mathrm{P}$ spectrum, is also assigned to $\mathrm{PPh}_{3}$. Apparently, triphenylphosphine is entrained in the composite matrix during the reaction of the starting $\mathrm{Ru}$ complex with BP-1 loaded with PONOP. Repeated washings with toluene failed to remove all of it, but did decrease the relative 
intensity of the ${ }^{31} \mathrm{P}$ NMR resonance at $\delta$ 44.4. The $\mathrm{Cl}$ analysis for method 1 gives a value of $0.076 \mathrm{mmol} / \mathrm{g}$ while the phosphorous analysis gives $0.060 \mathrm{mmol} / \mathrm{g}(\mathrm{P} / \mathrm{Cl}=0.79)$. Theoretically there should be twice as much phosphorous per gram but the higher $\mathrm{Cl}$ content can be attributed to residual chloride from unreacted chloropropyl groups after polyamine anchoring to the silica gel $(\mathrm{Cl}$ content in $\mathrm{BP}-1$ is $0.21 \%$ or $0.060 \mathrm{mmol} / \mathrm{g})$. However, for methods 2 and 3 the $\mathrm{P} / \mathrm{Cl}$ ratio decreases to 0.35 and 0.38 suggesting the introduction of chlorine during the immobilization reaction probably via dehydrohalogenation of the Ru complex by basic amine sites (Table 1A). Dehydrohalogenation of a RuPONOP pincer complex to give an $\mathrm{Ru}^{0}$ has been previously reported. ${ }^{48}$

Table 1A: CPMAS ${ }^{13} \mathrm{C}$ and ${ }^{31} \mathrm{P}$ NMR data and Elemental Analyses for Composite 1

\begin{tabular}{|c|c|c|c|c|}
\hline Method & $\begin{array}{c}\text { CPMAS } \\
{ }^{31} \mathrm{P} \operatorname{NMR}(\delta)\end{array}$ & $\mathrm{CPMAS}^{13} \mathrm{C}$ NMR $(\delta$ ppm $)$ & Elemental Analysis & $\mathrm{P} / \mathrm{Cl}$ \\
\hline 1 & 58.1 & $\begin{array}{c}163.5 \text { (pyridine), } 48.5\left(\mathrm{CH}_{2} \text { polyamine }\right), \\
33.8 \text { (tert-butyl), } 23.9 \text { (tert-butyl), } \\
-5.9\left(\mathrm{Si}_{-} \mathrm{CH}_{3}\right)\end{array}$ & $\begin{array}{l}\text { C } 12.57 \%, \mathrm{H} 2.75 \%, \mathrm{~N} \\
2.42 \%, \mathrm{P} 0.189 \%, \mathrm{Cl} 0.27 \%\end{array}$ & 0.79 \\
\hline 2 & $58,44.4$ & $\begin{array}{c}163.2 \text { (pyridine), } 129.7\left(\mathrm{PPh}_{3}\right), 49.9 \\
\left(\mathrm{CH}_{2} \text { polyamine }\right), 35.1 \text { (tert-butyl), } \\
25.4 \text { (tert-butyl), - } 4.7\left(\mathrm{Si}-\mathrm{CH}_{3}\right)\end{array}$ & $\begin{array}{l}\mathrm{C} 14.16 \%, \mathrm{H} 2.94 \%, \mathrm{~N} \\
2.62 \%, \mathrm{P} 0.502 \%, \mathrm{Cl} 1.65 \%\end{array}$ & 0.35 \\
\hline 3 & $58,44.4$ & $\begin{array}{c}163.2 \text { (pyridine), } 129.7\left(\mathrm{PPh}_{3}\right), 49.9 \\
\left.\left(\mathrm{CH}_{2} \text { polyamine }\right), 35.1 \text { (tert-butyl }\right), \\
25.4 \text { (tert-butyl), - } 4.7\left(\mathrm{Si}-\mathrm{CH}_{3}\right)\end{array}$ & $\begin{array}{l}\text { C } 13.77 \%, \mathrm{H} 2.84 \%, \mathrm{~N} \\
2.52 \%, \mathrm{P} \quad 0.489 \%, \mathrm{Cl} 1.50 \%\end{array}$ & 0.38 \\
\hline
\end{tabular}

The formation of $\mathrm{BP}-1-[(\mathrm{PONOP}) \mathrm{PdCl}] \mathrm{Cl}(2)$, by all three methods gave relatively sharp resonances at $\delta 33.3$ and 23.2 for the tert-butyl carbons and a broad resonance at $\delta 162.9$ for the pyridine moiety in the CPMAS ${ }^{13} \mathrm{C}$ NMR spectra. The resonances associated with the polymer appear at $\delta 48.4$ and a single broad peak is observed for ${ }^{31} \mathrm{P} \mathrm{NMR}$ at $\delta 65$. As for $\mathbf{1}$ the same pattern of resonances is observed for 2 made for by method 2 or 3 but with small differences in 
chemical shifts (Table $1 \mathrm{~B})$. The $\mathrm{P} / \mathrm{Cl}$ ratio for method 1 is 0.61 when it should be 1 , even lower than for $\mathbf{1}$. Here, as for $\mathbf{1}$ the $\mathrm{P} / \mathrm{Cl}$ ratio decreases by the about the same amounts on going from method 1 to methods 2 and 3. In this case however, formation of $\mathrm{PdCl}_{2}$ amine complexes in competition with PONOP is probably the reason, even in the case of method 1. There is considerable precedent in our prior work for the high affinity of the silica polyamine surface for $\operatorname{Pd}^{2+51}$

Table 1B: CPMAS ${ }^{13} \mathrm{C}$ and ${ }^{31} \mathrm{P}$ NMR data and Elemental Analyses for Composite 2

\begin{tabular}{|c|c|c|c|c|}
\hline Method & $\begin{array}{l}\operatorname{CPMAS}^{31} \mathrm{P} \\
\operatorname{NMR}(\delta)\end{array}$ & CPMAS ${ }^{13} \mathrm{C}$ NMR $(\delta)$ & Elemental Analyses & $\mathrm{P} / \mathrm{Cl}$ \\
\hline 1 & 65 & $\begin{array}{l}162.9 \text { (pyridine), } 48.4\left(\mathrm{CH}_{2} \text { polyamine }\right), \\
33.3(\text { tert-butyl }), 23.2 \text { (tert-butyl), } \\
-6.1\left(\mathrm{Si}-\mathrm{CH}_{3}\right)\end{array}$ & $\begin{array}{l}\text { C } 11.79 \%, \text { H } 1.89 \% \text {, N } 1.95 \% \text {, } \\
\text { P } 0.161 \%, \text { Cl } 0.30 \%\end{array}$ & 0.61 \\
\hline 2 & 65 & $\begin{array}{l}162.9 \text { (pyridine), } 48.4\left(\mathrm{CH}_{2} \text { polyamine }\right), \\
33.3(\text { tert-butyl }), 23.2 \text { (tert-butyl), } \\
\text { - } 6.1\left(\mathrm{Si}-\mathrm{CH}_{3}\right)\end{array}$ & $\begin{array}{l}\text { C } 12.78 \%, \text { H } 2.31 \%, \text { N } 2.22 \% \text {, } \\
\text { P } 0.495 \%, \text { Cl } 1.42 \%\end{array}$ & 0.38 \\
\hline 3 & 65.1 & $\begin{array}{l}\text { 162.8 (pyridine), } 48.2\left(\mathrm{CH}_{2} \text { polyamine }\right), \\
33.2 \text { (tert-butyl), } 23.1 \text { (tert-butyl), } \\
\text { - } 6.3\left(\mathrm{Si}-\mathrm{CH}_{3}\right)\end{array}$ & $\begin{array}{l}\text { C } 12.18 \%, \text { H } 2.10 \% \text {, N } 2.12 \% \text {, } \\
\text { P } 0.483 \% \text {, Cl } 1.29 \%\end{array}$ & 0.44 \\
\hline
\end{tabular}

As for 1 and 2, BP-1-[(PONOP)NiCl]Cl (3) exhibited the usual resonances in the CPMAS ${ }^{13} \mathrm{C}$ NMR at $\delta 165.6$ for the pyridine ring and $\delta 34.3 \& 25.6$ for the tert-butyl carbons respectively. The CPMAS ${ }^{31} \mathrm{P}$ NMR showed a resonance at $\delta$ 63.6. Overall this pattern is very similar to $\mathbf{2}$ and the chemical shifts were very similar for all three methods. However, in the case of 3 the resonances associated with the silanes are shifted slightly down-field. Although the actual $\mathrm{P} / \mathrm{Cl}$ ratios are somewhat different the overall pattern is similar to that for $\mathbf{2}$ with the 
amount of $\mathrm{Cl}$ increasing for methods 2 and 3 increasing relative to 1 and indicating competitive formation of $\mathrm{NiCl}_{2}$ amine complexes in competition with complexes of PONOP.

Table 1C: CPMAS ${ }^{13} \mathrm{C}$ and ${ }^{31} \mathrm{P}$ NMR data and Elemental Analyses for Composite 3

\begin{tabular}{|c|c|c|c|c|}
\hline Method & $\begin{array}{c}\text { CPMAS } \\
{ }^{31} \operatorname{PNMR}(\delta)\end{array}$ & CPMAS ${ }^{13} \mathrm{C}$ NMR $(\delta)$ & Elemental Analyses & $\mathrm{P} / \mathrm{Cl}$ \\
\hline 1 & 63.6 & $\begin{array}{c}165.6 \text { (pyridine), } 50.2\left(\mathrm{CH}_{2}\right. \\
\text { polyamine), } 34.3 \text { (tert-butyl), } 25.6 \\
\text { (tert-butyl }),-4.6\left(\mathrm{Si}-\mathrm{CH}_{3}\right)\end{array}$ & $\begin{array}{c}\mathrm{C} 11.68 \%, \mathrm{H} 2.12 \%, \mathrm{~N} 1.55, \\
\text { P } 0.118 \%, \mathrm{Cl} 0.21 \%\end{array}$ & 0.64 \\
\hline 2 & 63.6 & $\begin{array}{c}165.6 \text { (pyridine), } 50.2\left(\mathrm{CH}_{2}\right. \\
\text { polyamine), } 34.3 \text { (tert-butyl }), 25.6 \\
\text { (tert-butyl), }-4.6\left(\mathrm{Si}-\mathrm{CH}_{3}\right)\end{array}$ & $\begin{array}{c}\mathrm{C} 12.49 \%, \mathrm{H} 2.62 \%, \mathrm{~N} \\
1.95 \%, \mathrm{P} 0.497 \%, \mathrm{Cl} 1.10 \%\end{array}$ & 0.52 \\
\hline 3 & 63.5 & $\begin{array}{c}165.4 \text { (pyridine), } 50\left(\mathrm{CH}_{2}\right. \\
\text { polyamine }), 34.1(\text { tert-butyl }), 25.4 \\
(\text { tert-butyl }),-4.89\left(\mathrm{Si}-\mathrm{CH}_{3}\right)\end{array}$ & $\begin{array}{c}\mathrm{C} 13.48 \%, \mathrm{H} 2.41 \%, \mathrm{~N} \\
1.95 \%, \mathrm{P} 0.487 \%, \mathrm{Cl} 1.08 \%\end{array}$ & 0.52 \\
\hline
\end{tabular}

BP-1-(PONOP)RhCl (4) made by method 1 exhibited the expected tert-butyl resonance at $\delta 32.8$ and 23.6 and also a broad resonance at $\delta 164.5$ for the pyridine moiety and the usual resonances associated with the polymer. When made by methods 2 and 3 a resonance $\delta 126.6$ assignable to the phenyl groups on triphenylphosphine in the CPMAS ${ }^{13} \mathrm{C}$ NMR and the ${ }^{31} \mathrm{P}-$ NMR spectrum showed two resonances a major resonance at $\delta 60.5 \mathrm{ppm}$ assigned to phosphorus atoms in the complex and an additional resonance at $\delta 30.9$ assignable to triphenylphosphine. From this data it would appear that triphenylphosphine is trapped in the pores of the silica gel in the process of formation of 4 and 1 with methods $2 \& 3$. The composite 4 made by method 1 showed almost same resonances for tert-butyl and pyridine carbons, however, the silane resonance is slightly shifted to downfield. The $\mathrm{P} / \mathrm{Cl}$ ratio for the synthesis of $\mathbf{4}$ by method 1 is lower than for $\mathbf{1}$ even after correcting for the residual $\mathrm{Cl}$ due to chloroprpopyl silane. The reason for this is not clear at this time. The $\mathrm{P} / \mathrm{Cl}$ ratios observed for 4 made by methods 2 and 3 are 
higher than for $\mathbf{1}$ indicating that there is more entrapped triphenylphosphine than for $\mathbf{1}$. It remains to be seen whether the presence of excess phosphine will interfere with future catalytic studies.

The elemental analyses reported in Tables 1A-1D leave a lot to be desired with regard to determining actual pincer complex loading in light of the side reactions that give rise to excess $\mathrm{Cl}$ in all cases even using method $\mathbf{1}$ and the presence of excess phosphine in the case of $\mathbf{4}$ and $\mathbf{1}$ with methods $2 \& 3$. However, a comparison of the metal loading with the phosphorous analysis should considerably clarify the situation. The results of the metal analysis obtained by digestion of $1-4$ along with the calculated metal loading and its comparison with phosphine loading are given in Table 2 .

Table 1D: CPMAS ${ }^{13} \mathrm{C}$ and ${ }^{31} \mathrm{P}$ NMR data and Elemental Analyses for Composite 4

\begin{tabular}{|c|c|c|c|c|}
\hline Method & $\begin{array}{l}\text { CPMAS } \\
{ }^{31} \text { P NMR } \\
(\delta)\end{array}$ & CPMAS ${ }^{13} \mathrm{CNMR}(\delta)$ & Elemental Analyses & $\mathrm{P} / \mathrm{Cl}$ \\
\hline 1 & 60.8 & $\begin{array}{c}164 \text { (pyridine), } 49.4\left(\mathrm{CH}_{2} \text { polyamine }\right) \\
34.4 \text { (tert-butyl), } 24.3 \text { (tert-butyl), } \\
-5.1\left(\mathrm{Si}-\mathrm{CH}_{3}\right)\end{array}$ & $\begin{array}{c}\mathrm{C} 12.58 \%, \mathrm{H} 2.42 \%, \mathrm{~N} \\
1.53 \%, \mathrm{P} 0.143 \%, \mathrm{Cl} 0.24 \%\end{array}$ & 0.68 \\
\hline 2 & $\begin{array}{l}60.5 \\
30.9\end{array}$ & $\begin{array}{c}164.5 \text { (pyridine), } 126.6\left(\mathrm{PPh}_{3}\right), 48.5\left(\mathrm{CH}_{2}\right. \\
\text { polyamine), } 32.8 \text { (tert-butyl), } \\
23.6 \text { (tert-butyl), }-6.3\left(\mathrm{Si}-\mathrm{CH}_{3}\right)\end{array}$ & $\begin{array}{c}\mathrm{C} 14.89 \%, \mathrm{H} 2.83 \%, \mathrm{~N} \\
2.43 \%, \mathrm{P} 0.516 \%, \mathrm{Cl} 1.46 \%\end{array}$ & 0.41 \\
\hline 3 & $\begin{array}{l}60.5 \\
30.9\end{array}$ & $\begin{array}{c}164.5 \text { (pyridine), } 126.6\left(\mathrm{PPh}_{3}\right), 48.5\left(\mathrm{CH}_{2}\right. \\
\text { polyamine), } 32.8 \text { (tert-butyl), } 23.6 \text { (tert- } \\
\text { butyl), - } 6.36\left(\mathrm{Si}^{-} \mathrm{CH}_{3}\right)\end{array}$ & $\begin{array}{c}\mathrm{C} 14.75 \%, \mathrm{H} 2.73 \%, \mathrm{~N} \\
2.13 \%, \mathrm{P} 0.508 \%, \mathrm{Cl} 1.43 \%\end{array}$ & 0.40 \\
\hline
\end{tabular}

Comparing $\% \mathrm{P}$ from elemental analysis with the $\% \mathrm{Ru}$ from metal analysis for $\mathbf{1}$, made by methods 1 and 2, the loadings of 1 are in reasonable agreement, being $0.031 \mathrm{mmol} / \mathrm{g}$ and $0.039 \mathrm{mmol} / \mathrm{g}$ for method 1 and 0.068 and 0.081 for method 2 , for the two analytical methods (Table 2). In the case of $\mathbf{3}$ both methods 1 and 3 give reasonable agreement between the results 
of metal digestion and phosphorus analysis, being 0.014 and $0.019 \mathrm{mmol} / \mathrm{g}$ and $0.069 \mathrm{mmol} / \mathrm{g}$ and $0.078 \mathrm{mmol} / \mathrm{g}$, respectively (Table 2 ). However, the data for method 2 shows poor agreement between values for phosphorus and metal analysis. All three methods used for composite 2 gave very high Pd values relative to the phosphorus content. This is consistent with the high chloride content and points to the competitive formation of $\mathrm{PdCl}_{2}$ polyamine complexes. In all three methods the pincer ligand to total $\mathrm{Pd}$ is $\sim 1: 3$. However, even the high $\mathrm{Cl}$ content cannot account for all the Pd, suggesting the formation of Pd nanoparticles as has been previously reported for $\mathrm{Pd}$ salts on $\mathrm{BP}-1^{[31,38]}$ in addition to the formation of $\mathrm{PdCl}_{2}$-amine complexes. Interestingly, only method 2 for complex $\mathbf{3}$ shows a significant excess of metal and

Table 2: Loading of Metal or Complex on BP1 (mmol of ligand or complex / $\mathrm{g}$ of BP-1

\begin{tabular}{|c|c|c|c|c|c|}
\hline Composite & $\begin{array}{c}\text { Method of } \\
\text { loading }\end{array}$ & $\begin{array}{c}\text { mmol/g } \\
\text { complex by } \\
\text { AAS }\end{array}$ & $\begin{array}{c}\text { mmol/g ligand from } \\
\text { P analysis }\end{array}$ & $\begin{array}{c}\text { RSD for metal } \\
\text { analysis } \\
( \pm \%)\end{array}$ & $\begin{array}{c}\text { \% N sites } \\
\text { loaded }\end{array}$ \\
\hline \multirow{3}{*}{1} & Method 1 & $\mathbf{0 . 0 3 9}$ & $\mathbf{0 . 0 3 1}$ & $\mathbf{2 . 5 0}$ & $\mathbf{2 . 4 4}$ \\
\cline { 2 - 6 } & Method 2 & $\mathbf{0 . 0 6 8}$ & $\mathbf{0 . 0 8 1}$ & $\mathbf{1 . 8 0}$ & $\mathbf{4 . 2 5}$ \\
\cline { 2 - 6 } & Method 3 & $\mathbf{0 . 0 4 5}$ & $\mathbf{0 . 0 7 9}$ & $\mathbf{2 . 4 0}$ & $\mathbf{2 . 8 1}$ \\
\hline \multirow{3}{*}{2} & Method 1 & $\mathbf{0 . 0 8 1}$ & $\mathbf{0 . 0 2 6}$ & $\mathbf{0 . 1 5}$ & $\mathbf{5 . 0 6}$ \\
\cline { 2 - 6 } & Method 2 & $\mathbf{0 . 2 4 4}$ & $\mathbf{0 . 0 8 0}$ & $\mathbf{0 . 0 5}$ & $\mathbf{1 5 . 2 5}$ \\
\cline { 2 - 6 } & Method 3 & $\mathbf{0 . 2 3 0}$ & $\mathbf{0 . 0 7 8}$ & $\mathbf{0 . 0 1}$ & $\mathbf{1 4 . 3 8}$ \\
\hline \multirow{3}{*}{3} & Method 1 & $\mathbf{0 . 0 1 4}$ & $\mathbf{0 . 0 1 9}$ & $\mathbf{0 . 8 9}$ & $\mathbf{0 . 8 8}$ \\
\cline { 2 - 6 } & Method 2 & $\mathbf{0 . 1 3 9}$ & $\mathbf{0 . 0 8 0}$ & $\mathbf{0 . 3 5}$ & $\mathbf{8 . 6 9}$ \\
\cline { 2 - 6 } & Method 3 & $\mathbf{0 . 0 6 9}$ & $\mathbf{0 . 0 7 8}$ & $\mathbf{0 . 3 3}$ & $\mathbf{4 . 3 1}$ \\
\hline \multirow{3}{*}{4} & Method 1 & $\mathbf{0 . 0 1 5}$ & $\mathbf{0 . 0 2 3}$ & $\mathbf{1 . 2 0}$ & $\mathbf{2 . 6 3}$ \\
\cline { 2 - 6 } & Method 2 & $\mathbf{0 . 0 4 2}$ & $\mathbf{0 . 0 8 3}$ & $\mathbf{0 . 0 8 2}$ & $\mathbf{2 . 4 4}$ \\
\cline { 2 - 6 } & Method 3 & $\mathbf{0 . 0 3 9}$ & $\mathbf{0 . 0 8 2}$ & & \\
\hline
\end{tabular}

this can be accounted for by the formation of $\mathrm{NiCl}_{2}$ polyamine complexes if one assumes that all the pincers are complexed to $\mathrm{Ni}(0.14 \mathrm{mmol} \mathrm{Ni} / \mathrm{g}$ total $0.08 \mathrm{mmol} / \mathrm{g}$ for pincer, $0.31 \mathrm{mmol} / \mathrm{g}$ total $\mathrm{Cl}, 0.16$ needed for pincer, leaving $0.15 \mathrm{mmol} / \mathrm{g}$ excess chloride and 0.060 excess nickel that requires $0.12 \mathrm{Cl}$, adding the $0.060 \mathrm{mmol} / \mathrm{g}$ for residual chloropropyl gives a good $\mathrm{Cl}$ mole 
balance for 3). Composite 4 gave low loading by method 1 but with comparable values between $\mathrm{P}$ and Rh loading. Methods 2 and 3 showed high phosphorus values as a result of entrained triphenylphosphine that was detected by CPMAS ${ }^{13} \mathrm{C}$ and ${ }^{31} \mathrm{P}$ NMR (Table $1 \mathrm{~A}$ and $\left.1 \mathrm{D}\right)$. Overall methods 2 and 3 provide higher metal loadings as a result of better loading of the ligand to the surface but there was evidence of side reactions that resulted in the formation of metal-halidepolyamine complexes in the case of $\mathbf{2}$ and $\mathbf{3}$ and metal nanoparticles in the case of $\mathbf{2}$. Thus method 1 gives cleaner results at the expense of higher loadings relative to methods 2 and 3 .

$1 \mathrm{~g}$ of BP-1 contains $1.6 \mathrm{mmol}$ of nitrogen $(\mathrm{N})$ sites based on its elemental analysis [8]. One could expect higher loading of the pincers considering the availability of amine densities on the BP-1 surface. In fact, all amine functionality might not be readily accessible to bind with metal pincers due to the steric hindrance of the bulky pincer complexes. The $\%$ of $\mathrm{N}$ sites on $\mathrm{BP}-$ 1 occupied with four pincer complexes by the three methods has been estimated from the ratio of $\mathrm{mmol} \mathrm{metal} / \mathrm{g}$ to the $\mathrm{mmol} \mathrm{N} / \mathrm{g}$. The overall nitrogen site occupancy by actual pincer-metal complexes is in the range of $1-4 \%$ (Table 2). The higher values reported in Table 2 for 2 are due to competitive metal loading via halide-polyamine complexes and/or Pd nanoparticles. The lower amounts (1-4\%) should be sufficient for catalytic studies based on some of our preliminary data. $[14,38]$

The impact of immobilization of the PONOP metal pincer complexes on surface area, structure and porosity of the silica polyamine composite,BP-1 was assumed to be very negligible particularly considering the extent of loading of the pincers $(<0.3$ mmol complex /g BP-1) (Table 2). Our previous studies on covalent tethering of luminescent Ru complexes on BP-1 with 
similar loading did not show any measurable changes in the porosity and structure of the composite surface. ${ }^{[14,38]}$

\subsection{Determination of the regiochemistry of the Mannich reaction with the PONOP ligand} in solution

The actual position of electrophilic aromatic substitution of the pyridine ring by the imine intermediate in the Mannnich reaction could not be determined from the solid-state NMR data due to the poor resolution of the aromatic resonances. Substitution at the meta-position would be expected on electronic grounds while para-substitution might be expected on steric grounds. In an attempt to clarify this point, n-butyl amine was treated with $38 \%$ formaldehyde, which yielded the imine intermediate. Then the PONOP ligand was added to the imine intermediate in a second step, which yielded a mixture of isomeric products (Equation 1). ${ }^{31} \mathrm{P}$ NMR spectra of the product mixture displayed three resonances 3 resonances (Figure 1a). A broad resonance at $\delta 117.13$ integrated in approximately a 1:1 ratio with a resonance at $\delta 112.46$. The broadness of the resonance at $\delta 117.13$ is attributed to hindered rotation of the tert-butyl groups of one of the phosphorus atoms of the PONOP ligand as a result of steric crowding with the n-butyl group in

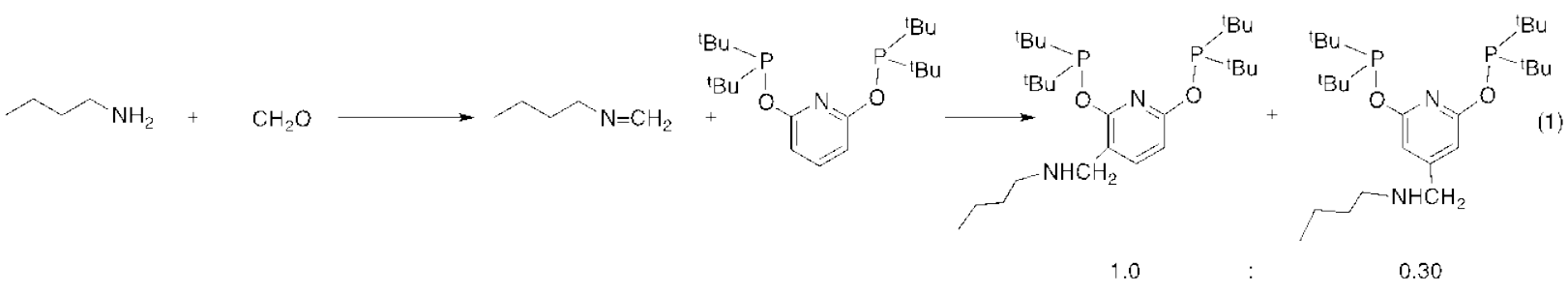

the meta-position. It represents the partial averaging of different conformations of the di-tertbutyl group. As expected the para-isomer exhibits only one resonance at $\delta 118.62$ and integrates in a ratio of $0.3: 1$ with the meta-isomer resonances. 

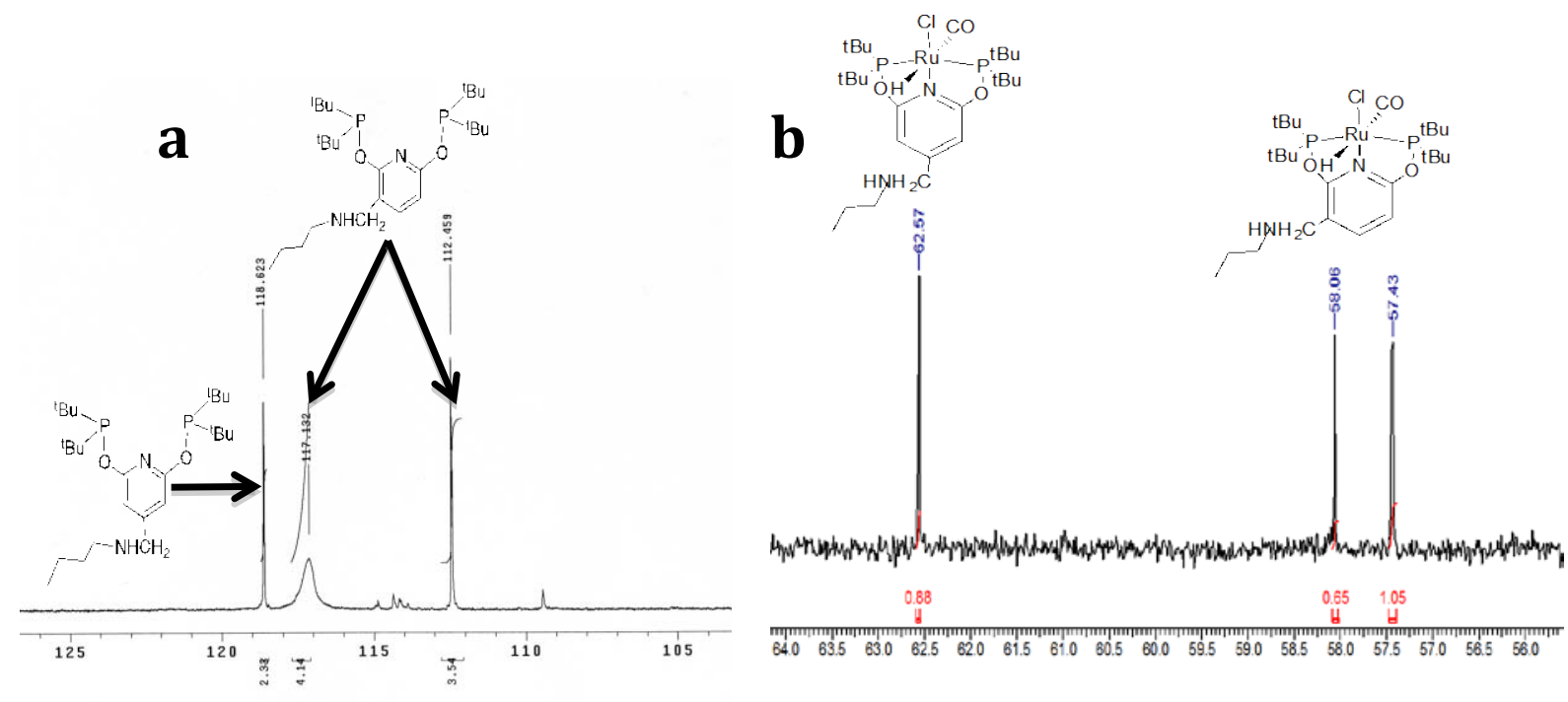

Figure 1: ${ }^{31} \mathrm{P}$ NMR spectrum of the isomers formed from the reaction of $\mathrm{n}$-butylamine with PONOP at $206 \mathrm{MHz}$ (a); and the isomers formed from the reaction of n-butylamine with $\mathrm{Ru}(\mathrm{PONOP})$ at $169 \mathrm{MHz}(\mathbf{b})$

Given that using the preassembled metal complex proved to be the best way to bind the pincer complexes to the SPC surface we thought it would be relevant to repeat the reaction sequence shown in equation 1 with $\mathrm{Ru}(\mathrm{PONOP})$. The results are remarkably similar. Again two isomers are obtained in a 0.3:1 para- to meta- ratio and in very similar yield (57\% for $\mathrm{Ru}(\mathrm{PONOP})$ and $60 \%$ for PONOP) (Figure $1 \mathrm{~b}$ ). This illustrates that the presence of the metal has little influence on the regiochemistry and the efficiency of the Mannich reaction with the PONOP system. However, the broadness of one of the ${ }^{31} \mathrm{P}$ resonances seen in the PONOP reaction is not observed in the reaction of the $\mathrm{Ru}(\mathrm{PONOP})$ with $\mathrm{n}$-butyl amine. This is not surprising in light of the geometry changes of the $\left({ }^{\mathrm{t}} \mathrm{Bu}\right)_{2} \mathrm{P}$ groups relative to the meta-nbutylamine that occur on coordination of $\mathrm{Ru}^{2+}$. It is also worthy of noting that the ${ }^{31} \mathrm{P}$ chemical shifts of the $\mathrm{Ru}(\mathrm{PONOP})$ resonances in solution are very similar to those observed in the solid state being $\delta 60.57,58.06,57.43$ (Table 1A). In addition, the CO stretching frequency is observed at $1942 \mathrm{~cm}^{-1}$ while the unsubstituted complex shows a CO stretching frequency of 1932 
$\mathrm{cm}^{-1}$. This clearly indicates the sensitivity of the CO stretch to environment and taken together with the solution ${ }^{31} \mathrm{P}$ NMR data provides further proof that the pincer ligand structure is conserved on grafting to the SPC surface.

\section{Conclusions}

Three methods have been attempted for immobilization of the PONOP pincer ligand complexes on BP-1. Four different metal PONOP pincer complexes, (PONOP)RuHCl(CO), [(PONOP)PdCl]Cl, [(PONOP)NiCl]Cl, and (PONOP)RhCl have been synthesized on BP-1 by these methods through the covalent linkage between PONOP ligand of the pincers and amine functionality on BP-1 surface. Solid-state CPMAS ${ }^{13} \mathrm{C}$ NMR of the complexes on BP-1 showed characteristic resonances for the tert-butyl and pyridine carbons of the complexes and the CPMAS ${ }^{31} \mathrm{P}$ NMR spectra provided the expected phosphine resonances, confirming the anchoring of the complexes to the composite. Method 1 provided the cleanest results with little evidence of side reactions as indicated by the relatively good agreement between the percent phosphorus and percent metal loading on the polyamine surface. Methods 2 and 3, where the PONOP ligand was bound to the composite surface first or constructed on the surface followed by addition of a metal complex gave better loading but were complicated by the formation of amine complexes in the case of $\mathrm{Ni}$ and $\mathrm{Pd}$ as well as metal nanoparticles in the case of $\mathrm{Pd}$. Similarly, immobilization of Ru and Rh PONOP pincers by methods 2 and 3 gave very high percentages of phosphorus relative to loaded metal as a result of entrainment of triphenylphosphine during reaction of the pincer ligand with starting poly-phosphine complexes. In the case of $\mathrm{Pd}$ and $\mathrm{Ni}$, the amine complexes formed in methods 2 and 3 would complicate catalytic studies as would the formation of the Pd nanoparticles in the case of composite 2 . It is less clear if the presence of triphenylphosphine on the composite would interfere with catalytic 
studies in the case of $\mathbf{1}$ and $\mathbf{4}$ and it might be adventitious to use the higher loading obtained with methods 2 and 3. However, our initial focus will certainly be on method 1 for future studies. We chose to begin these immobilization studies with the PONOP ligand because its relative air stability that allowed us to explore different approaches to immobilization. It should be pointed out here that the related PNN and PNP pincer ligands would provide more stable metal complexes because of their better donor properties. These studies and the catalytic applications of the resulting immobilized catalysts are underway in our laboratory. ${ }^{[52]}$ The solution model reactions showed the formation of both para- and meta- isomers but the solid-state ${ }^{31} \mathrm{P}$ NMR only shows one broad resonance making it difficult to conclude whether the same regiochemistry persists in the immobilized complexes.

\section{Acknowledgement}

The authors gratefully acknowledge the support of Grantfrom the National Science Foundation (CHE-1049567)

\section{References:}

1. J. Choi,; Y. Choliy, X. W. Zhang,; T. J. Emge, K. Krogh-Jespersen, A. S. Goldman, J. Am. Chem. Soc. 2009, 131, 15627-15629.

2. Z. Huang, M. Brookhart, A. S. Goldman, S. Kundu, A. Ray, S. L. Scott, B. C. Vicente, Adv. Synth. Catal. 2009, 351, 188-206.

3. A. S. Goldman, A. H. Roy, Z. Huang, R. Ahuja, W. Schinski, M. Brookhart, Science 2006, 312, 257-261.

4. A. Castonguay, A. L. Beauchamp, D. Zargarian, Organometallics 2008, 27, 5723-5732.

5. R. Tanaka, M. Yamashita, K. Nozaki, J. Am. Chem. Soc. 131 (2009), 14168-14169.

6. K. Arashiba, Y. Miyake, Y. Nishibayashi, Nature Chem. 2011, 3, 120-125. 
7. G. Muller, M. Klinga, M. Leskela, B. Rieger, Z. Anorg. Allg. Chem. 2002, 628, 2839-2846.

8. S. Chakraborty, J. A. Krause, H. Guan, Organometallics 2009, 28, 582-586.

9. D. Morales-Morales, C. Jensen, The Chemistry of Pincer Compounds, Elsevier Science: Amsterdam, 2007.

10. V. Udayakumar, S. Alexander, V. Gayathri, V. Shivakumaraiah, K.R. Patil, B. Viswanathan, J. Mot. Catal. A: Chem. 2010, 317, 111-117.

11. B. H. G. Swennenhuis, R. Chen, P. W. N. M. van Leeuwen, J. G. deVries, P. C. J. Kamer, Eur. J. Org. Chem. 2009, 33, 5796-5803.

12. E. Karakhanov, A. Maximov, Metal Complexes and Metals in Macromolecules (Eds.: D. Wohrle, A. Pomogajlo), John Wiley \& Sons: New York, 2003, p. 457.

13. E. Karakhanov, A. Maximov, Y. Kardasheva, V. Semernina, A. Zolotukhina, A. Ivanov, G. Abbott, E. Rosenberg, ACS Appl. Mater. Interfaces 2014, 6, 8807-8816.

14. G. Abbott, R. Brooks, E. Rosenberg, M. Terwilliger, J. B. Alexander Ross, O. L. Ichire Organometallics 2014, 33, $2467-2478$.

15. B. Tamami, M.M. Nezhad, S. Ghasemi, F. Farjadian, J. Organomet. Chem. 2013, 743, $10-16$.

16. M. Berlin, J. Allen; V. Kailasam, D. Rosenberg, E. Rosenberg, Appl. Organometal. Chem. 2011, 25, 530-536.

17. H.U. Blaser, B., Pugin, M. Studer, in: Chiral Catalyst Immobilization and Recycle, eds. De Vos, D.E., Vankelecom, I.FJ. and Jacobs, P.A. (VCH, Weinheim, 2000) p. 9.

18. C.W. Jones, M.W. McKittrick, J.V. Nguyen, K. Yu, Topics in Catal. 2005, 34, 67-76.

19. C.D. Pozo, A. Corma, M. Iglesias, F. Sanchez, Organometallics 2010, 29, 4491. 
20. P.A. Chase, R.J.M. Klein Gebbink, G. van Koten, J. Organomet. Chem. 2004, 689, 4016-4054.

21. J.W.J. Knapen, A.W. van der Made, J.C. de Wilde, P.W.M.N. van Leeuwen, P. Wijkens, D.M. Grove, G. van Koten, Nature 1994, 372.

22. D.E. Bergbreiter, P.L. Osborn, J.D. Frels, J. Am. Chem. Soc. 2001, 123, 11105-11106.

23. N.C. Mehendale, J.R.A. Sietsma, K.P. de Jong, C.A. van Walree, R.J.M.K. Gebbink, G. van Koten, Adv. Synth. Catal. 2007, 349, 2619-2630.

24. N.C. Mehendale, C. Bezemer, C.A. van Walree, R.J.M.K. Gebbink, G. van Koten, J. of Molecular Catal. A: Chem. 2006, 257, 167-175.

25. A.R. McDonald, H.P. Dijkstra, B.M.J.M. Suijkerbuijk, G.P.M. van Klink, G. van Koten, Organometallics 2009, 28, 4689-4699.

26. W.J. Sommer, K. Yu, J.S. Sears, Y. Ji, X. Zheng, R.J. Davis, C.D. Sherrill, C.W. Jones, M. Weck, Organometallics 2005, 24, 4351-4361.

27. Z. Huang, M. Brookhart, A.S. Goldman, S. Kundu, A. Ray, S.L. Scott, B.C. Vicente, Adv. Synth. Catal. 2009, 351, 188-206.

28. B.C. Vicente, Z. Huang, M. Brookhart, A.S. Goldman, S.L. Scott, Dalton Trans. 2011, 40, 4268-4274.

29. M. Rimoldi, D. Fodor, J.A. van Bokhoven, A. Mezzetti, Chem. Commun. 2013, 49, 11314-11316.

30. K. Yu, W. Sommer, M. Weck, C.W. Jones, J. of Catal. 2004, 226, 101-110.

31. K. Yu, W. Sommer, J.M. Richardson, M. Weck, C.W. Jones, Adv. Synth. Catal. 2005, 347, 161-171. 
32 a) D. Milstein Top. Catal. 2010, 53, 915-923. b) R. Langer, Y. Diskin-Posner, G. Leitus, L. J. W. Shimon, Y. Ben-David, D. Milstein Angew. Chem. Int. Ed. 2011, 50, 9948 9952.

33. P. Kang, C. Cheng, Z. Chen, C. K. Schauer, T. J. Meyer,* and M. Brookhart J. Am. Chem. Soc. 2012, 134, 5500-5503

34. S. Chakraborty, J. A. Krause, H. Guan Organometallics 2009, 28, 582-586

35. N. Selander, K. J.Szabo, Chem. Rev. 2011, 111, 2048-2076.

36. M. Hughes, D. Nielsen, E. Rosenberg' R. Gobetto', A. Viale, S.D. Burton Ind. Eng. and Chem. Res. 2006 45, 6538.

37. S.T. Beatty, R. J. Fischer, D.L. Hagers, E. Rosenberg, Ind. Eng. Chem. Res. 1999, 38, 4402-4408.

38. Y. O. Wong, P. Miranda, E. Rosenberg, J. Appl. Poly. Sci. 2010, 115, 2855-2864.

39. M. Hughes, Paul Miranda, D.Nielsen, E. Rosenberg, R. Gobetto, A.Viale, S. Burton "Silica polyamine composites: new supramolecular materials for cation and anion recovery and remediation," in Recent Advances and Novel Approaches in Macromolecule-Metal Complexes, Eds, R. Barbucci, FCiardelli, G. Ruggeri, WileyVCH (Macromolecular Symposia 235), Weinheim, 2006, p 161.

40. S. Nishimura, Handbook of heterogeneous catalytic hydrogenation for organic synthesis, John Wiley \& Sons: New York, 2001.

41. J. M. Thomas, J. Mol. Catal. A: Chem. 1999, 146, 77-85.

42. J. Allen, E. Rosenberg, E. Karakhanov, S.V. Kardashev,; A. Maximov, A. Zolotukhina 
Appl. Organometal. Chem. 2011, 25, 245-254.

43. T. J. Bandosz, M. Seredych, J. Allen, J. Wood, E. Rosenberg, Chem. of Materials 2007, 19, 2500-2511.

44. E. Rosenberg, P. Miranda, W. Yuen Onn, U.S. Patent 8,343,446, 2012.

45. S. Kundu, W.W. Brennessel, W.D. Jones, Inorg. Chem. 2011, 50, 9443-9453.

46. Inorganic Syntheses, Vol. VI, p. 218, McGraw-Hill Book Company, NY

47. M.A. Andrews, T. C.-T. Chang, Chi-Wen. F. Cheng, T. J. Emge, K.P. Kelly, T.F. Koetzle, J. Am. Chem. Soc. 1984, 106, 5913-5920.

48. H. Salem, L.J.W. Shimon, Y. Diskin-Posner, G. Leitus, Y. Ben-David, D. Milstein, Organometallics 2009, 28, 4791-4806.

49. W.H. Bernskoetter, C.K. Schauer, K.I. Goldberg, M. Brookhart, Science 326 2009, 326, $553-556$.

50. M. Panigati, P Mercandelli, G. D.Õ. Alfonso, T. Berrenghelli, A. Sironi J. Organometal. Chem. 2005, 690, 2044-2051.

51. C. Anderson, E. Rosenberg, C. K. Hart, L. Ratz, Y. Cao Proceedings of the $5^{\text {th }}$ International Symposium on Hydrometallurgy, 2003, Volume 1 Leaching and Purification, Ed. Courtney Young, TMS, Warendale, PA, p393.

52. A. Goni and E.Rosenberg Abstracts 2015 ACS Northwest Regional that will be held in Pocatello, ID, June 21-24, 2015. Abstract \# 33. 
Methods Study of the Immobilization of PONOP pincer transition metal complexes on silica polyamine composites

Md Abdul Goni, Edward Rosenberg", Shesharao Meregude, Geoffrey Abbott

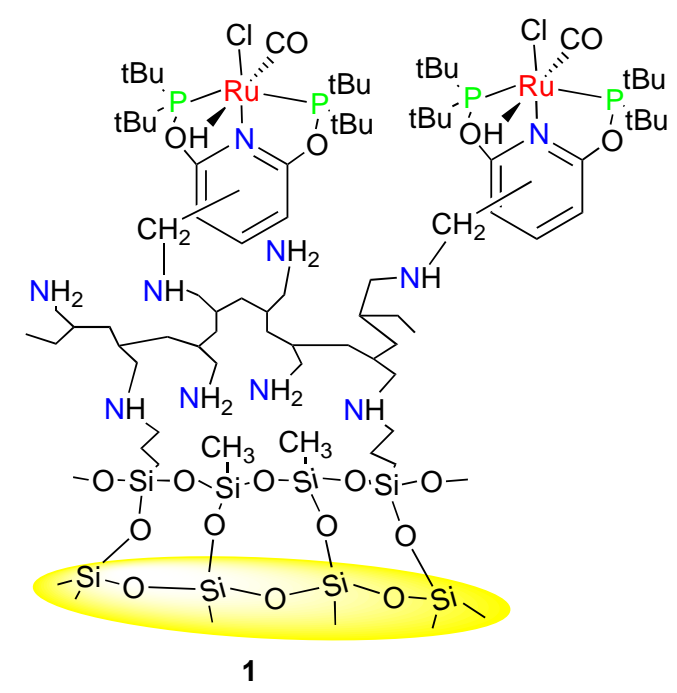

Three different methods of grafting a range of transition metal pincer complexes to the surface of silica polyamine composites have been studied. The best method uses the Mannich reaction and the preassembled complex. 